\title{
Modelling large plastic deformations of cohesive soils using sequential limit analysis
}

\author{
D. Kong, C. M. Martin*, B. W. Byrne \\ Department of Engineering Science, University of Oxford, Parks Road, Oxford OX1 3PJ, UK
}

\section{SUMMARY}

This paper introduces sequential limit analysis (SLA) as a method for modelling large plastic deformations of purely cohesive materials such as undrained clay. The method involves solving a series of consecutive small-deformation plastic collapse problems using finite element limit analysis, thus ensuring high levels of accuracy, efficiency and robustness. The techniques needed to develop an SLA implementation for 2D (plane strain) problems are described in detail, including model geometry updating routines, treatment of rigid

5 bodies, interfaces and boundaries, and periodic remeshing and interpolation of field variables. A simple total stress-based constitutive model is employed to account for strain softening and strain rate effects. Extensive verifications and validations are performed using analytical solutions and physical model test results, comparing both collapse loads and failure mechanisms, to demonstrate the effectiveness of the SLA approach. Additional solution quality checks on the bracketing discrepancy between lower bound and upper bound limit analysis solutions, and on the incompressibility of the rigid-plastic material, are also presented. Copyright (c) 2016 John Wiley \& Sons, Ltd.

6 Received ...

7 KEY WORDS: Numerical modelling; limit analysis; large deformation; remeshing; clay; pipeline

\footnotetext{
${ }^{*}$ Correspondence to: Department of Engineering Science, University of Oxford, Parks Road, Oxford OX1 3PJ, UK

$\dagger$ †lease ensure that you use the most up to date class file, available from the NAG Home Page at

http://www3.interscience.wiley.com/journal/3312/home

Copyright (c) 2016 John Wiley \& Sons, Ltd.

Prepared using nagauth.cls [Version: 2010/05/13 v2.00]
} 


\section{INTRODUCTION}

1.1. Background to sequential limit analysis

2 The foundations of limit analysis for perfectly plastic structures are the lower bound (LB) and

3 upper bound (UB) theorems of plasticity [1,2]. Together these theorems allow the exact collapse

4 load for the structure to be bracketed in a rigorous manner. When limit analysis is applied to $2 \mathrm{D}$

5 or 3D continua, exact solutions can only be obtained for certain simple problems. In general it is

6 necessary to obtain non-coincident LB and UB solutions numerically, either using bespoke stress

7 and velocity fields (e.g. [3, 4, 5, 6]) or via finite element limit analysis (FELA). Most of the early

8 implementations of FELA relied on linear programming optimisation techniques, which required

9 the yield function to be linearised (e.g. [7, 8, 9, 10, 11]). More recent FELA implementations have

10 tended to employ non-linear programming (e.g. [12, 13, 14, 15, 16, 17]) or conic programming (e.g.

$11[18,19,20,21,22,23])$ optimisation techniques. These allow a range of smooth and non-smooth

12 yield functions to be treated natively, without linearisation. 
1 be accounted for by updating the distribution of local material strengths used for each incremental

2 UB analysis.

3 It was shown in [24] that SLA can achieve reliable geometric updating even with much larger time

4 increments than those typically used in large-deformation finite element (FE) analysis, significantly

5 improving the computational efficiency. Moreover, as will be shown in this paper, SLA has an

6 advantage over large-deformation FE analysis of being highly stable under material and geometrical

7 nonlinearities, since no updating or interpolation of the stress field is required during the simulation.

8 It is important to note that successful application of the SLA approach has previously been confined

9 to relatively simple structural problems such as frames and plates, where contact and interface

10 conditions are not relevant $[24,25,26]$. To extend this method for the study of continuum problems,

11 the interfaces and external boundaries of the model have to be treated carefully. In addition, practical

12 applications involving continua frequently require consideration of the effects of strain softening and

13 strain rate on the material strength.

The SLA approach described here uses the in-house FELA code OxLim [18, 19, 21, 27], with Triangle [28] for 2D unstructured mesh generation and ParaView [29] for visualisation.

16 In an OxLim analysis, the application of the LB and UB theorems to a continuum region 17 (discretised into triangular finite elements) leads to two separate second-order cone programming 18 problems that are optimised using the commercial software MOSEK [30]. In the LB/UB analyses, 19 statically/kinematically admissible discontinuities are incorporated between elements to yield 20 more satisfactory solutions than those obtainable from fully continuous stress/velocity fields. In 21 principle, only UB analyses are needed for SLA modelling because each analysis increment involves geometric updating using just the computed velocity field. However, LB analyses can also be performed simultaneously in order to assess the accuracy of the computed UB solutions, by monitoring the gap between the bounds. A schematic overview of the SLA method employed here is shown in Figure 1. The whole process is automatically controlled by code written in Python. 


\subsection{Application to geotechnical problems}

2 When applying SLA to geotechnical problems involving large plastic deformations of cohesive soils

3 such as undrained clay, certain behaviours of the soil such as elastic response and consolidation

4 cannot be considered directly. Additionally, the velocity field obtained from a UB analysis using

5 FELA is not exact; instead a numerical optimisation problem is solved approximately, to a finite

6 tolerance, for a particular mesh discretisation. Over a sequence of such analyses, particularly

7 when there is remeshing at regular intervals, it is inevitable that some numerical error will

8 accumulate. Nevertheless, SLA can provide the most important information (collapse load and

9 failure mechanism) at a fraction of the cost of conventional incremental FE methods, making it

10 very attractive for large-deformation problems [24, 25]. To use SLA for practical applications it is

11 of course necessary that the deforming material can be reasonably idealised as rigid-plastic and

12 obeying an associated flow rule, as required by the theorems of limit analysis.

A number of other advanced numerical approaches are available for the analysis of geotechnical problems involving large plastic deformations. These include the material point method [31, 32,

15 33, 34], smoothed particle hydrodynamics [35, 36, 37, 38] and the distinct element method

16 [39, 40, 41, 42, 43, 44], though at present the most widely used approaches are FE-based 17 methods such as the arbitrary Lagrangian-Eulerian (ALE) [45, 46], remeshing and interpolation 18 technique with small strain (RITSS) [47, 48, 49, 50] and coupled Eulerian-Lagrangian (CEL) $19[51,52,53,54,55,56,57,58]$ techniques. The RITSS method originally developed in [47] is

an improved ALE approach which divides a large-deformation problem into a series of smalldeformation FE analyses. It can be seen that in this respect, the SLA method introduced here is similar to the RITSS method, but each SLA increment involves solving one or two computational limit analysis problems (UB and optionally LB) rather than performing an increment of conventional elastic-plastic FE analysis.

Where large plastic deformations of cohesive soil are caused by an indenter, penetrometer or foundation element that can be treated as a rigid body, and where the elastic deformation of the soil is of little importance to the solution, the proposed SLA method could potentially be 
1 more attractive than the other numerical approaches described above, considering the computing

2 efficiency. However, the focus of this paper is on demonstrating that the use of SLA for such

3 problems is satisfactorily accurate and efficient in its own right, rather than attempting to present

4 detailed comparisons between SLA and other methods. In any case, objective comparisons are

5 extremely difficult and impractical to achieve, as will be discussed in Section 4.2.

6 The techniques introduced in this paper for the treatment of rigid bodies can in principle be 7 applied to any convex polygon, although, for the sake of simplicity, these polygons are represented

8 by circles when schematic diagrams are provided. All of the examples studied here (plate, wedge, 9 strip footing, pipe segment, etc.) are plane strain problems involving interactions between rigid 10 bodies and undrained soil, which undergoes plastic deformation at constant volume. Although 11 similar SLA simulations could readily be undertaken with cohesive-frictional or purely frictional 12 materials, the assumption of associated flow (a requirement for any method based on classical limit that large deformations computed using SLA are unlikely to be of great practical value.

By employing an axisymmetric FELA solver, the present SLA approach could readily be adapted to analyse the vertical loading behaviour of rigid objects such as ball penetrometers or spudcan

17 footings in cohesive soils. Moreover, gravity-driven problems without rigid bodies, such as slope stability (e.g. [19, 21, 27]) and tunnel face collapse (e.g. [59, 60]) could also potentially be solved using SLA to model progressive large plastic deformations. These problems are, however, not investigated here since the emphasis is on soil-structure interactions.

\section{DEVELOPMENT OF MODELLING APPROACH}

\subsection{Updating of model geometry}

At a given increment in an SLA simulation, the coordinates of an individual node are updated by

$$
\vec{X}=\vec{x}+\vec{v} \cdot \Delta t
$$


1 where $\vec{x}$ and $\vec{X}$ are the coordinates at the beginning and end of the increment, $\vec{v}$ is the nodal velocity

2 from the UB velocity field, and $\Delta t$ is the incremental time step.

3 Because of the kinematically admissible velocity discontinuities employed in the UB analysis 4 using OxLim, nodes on the external boundary of the model, see Figure 2, may require velocity 5 averaging. This is illustrated in Figure 3, where an arbitrary node Q on the external boundary has 6 several evaluation points sharing the same coordinates, but having different velocity vectors. Three 7 types of external boundary node are recognised in Figure 2. Those on the free surface and not 8 in contact with the rigid body are termed surface nodes; those in contact with the rigid body but 9 adjacent to a surface node are termed margin nodes; and those between the two margin nodes are 10 termed interface nodes. The velocity of a surface node is simply determined as the average of the 11 velocity vectors corresponding to all of its evaluation points, and the nodal displacement is updated 12 accordingly using Equation 1. The positions of the interface nodes can be conveniently reconstructed 13 at each increment using the coordinates of the rigid body vertices, based on the assumption that 14 no separation occurs within the contact domain between the two margin nodes. The incremental 15 evolution of the contact domain can be achieved by tracking the positions of the margin nodes 16 relative to the rigid body; this procedure is explained below.

17 2.1.1. Velocity of a margin node After the UB velocity field has been obtained, each margin node 18 is checked to see whether it moves tangentially along the rigid body segment to which it is currently 
1 coordinates of its two endpoints. $\theta$ is the angle between $\left(\vec{v}_{(i)}-\vec{v}_{r}\right)$ and $\vec{s}$, and $\theta_{c r i}$ is the tolerance of

$2 \theta$ with a default value of $10^{-4} \mathrm{rad}$.

3 If Equation 2 is not satisfied for any evaluation point associated with the margin node, the node

4 is concluded to have broken away from the rigid body, and other nodes in the contact domain near

5 it are checked consecutively as illustrated in Figure $4 \mathrm{a}$, until an end node $\mathrm{n}_{(e)}$ satisfying Equation 2

6 is found. After that, the nodes $\mathrm{n}_{(0)}$ to $\mathrm{n}_{(e-1)}$ are released from the contact boundary and updated as

7 surface nodes, while node $\mathrm{n}_{(e)}$ is updated as the new margin node (see Figure $4 \mathrm{~b}$ ) and its velocity

$8 \quad \vec{v}_{\text {mar }}$ is determined as

$$
\vec{v}_{\text {mar }}=\frac{\sum\left\|\left(\vec{v}_{(i)}-\vec{v}_{r}\right) \cdot \vec{s}\right\|}{l \cdot\|\vec{s}\|} \cdot \frac{\vec{s}}{\|\vec{s}\|}+\vec{v}_{r}
$$

9 where $l$ is the total number of evaluation points associated with the margin node, which depends on 10 the local connectivity. This determination of $\vec{v}_{\text {mar }}$ ensures that the direction of $\left(\vec{v}_{\text {mar }}-\vec{v}_{r}\right)$ coincides 11 with that of $\vec{s}$, and that all the components of $\left(\vec{v}_{(i)}-\vec{v}_{r}\right)$ along $\vec{s}$ are averaged.

$$
k=\max \left(0, \operatorname{sign}\left[\left(\vec{v}_{\text {mar }}-\vec{v}_{r}\right) \cdot \vec{s}_{(m)}\right]\right)=0 \text { or } 1
$$


1 where $\vec{s}_{(m)}$ is the vector of the margin segment $\mathrm{S}_{(m)}$ (vertices $\left.\mathrm{P}_{(m)} \rightarrow \mathrm{P}_{(m+1)}\right)$. The time $d t$ that would

2 be required for the margin node to move to reach and coincide with $\mathrm{P}_{(m+k)}$ is calculated as

$$
d t=\frac{\left\|\vec{x}_{(m+k)}-\vec{x}_{\text {mar }}\right\|}{\left\|\vec{v}_{\text {mar }}-\vec{v}_{r}\right\|}
$$

3 where $\vec{x}_{(m+k)}$ and $\vec{x}_{m a r}$ are the coordinates of $\mathrm{P}_{(m+k)}$ and the margin node respectively. The time step

$4 \quad \Delta t$ used to update the model geometry is then determined as

$$
\Delta t=\min \left(d t, \Delta t_{\text {lim }}\right)
$$

5 where $\Delta t_{\text {lim }}$ is a limiting incremental time step set by the user. If $\Delta t_{\text {lim }}$ is chosen to update the nodal 6 coordinates, the margin node will remain on $\mathrm{S}_{(m)}$, though at a different intermediate position. If $d t$ 7 is chosen, the node will move to coincide with $\mathrm{P}_{(m+k)}$, which is exactly at the corner formed by 8 segments $\mathrm{S}_{(m)}$ and $\mathrm{S}_{(m+h)}$, where $\mathrm{S}_{(m+h)}$ is the potential segment that the node moves towards, with $9 h$ given by

$$
h=\operatorname{sign}\left[\left(\vec{v}_{m a r}-\vec{v}_{r}\right) \cdot \vec{s}_{(m)}\right]= \pm 1
$$

10 To carry on the analysis, the margin node is now forced to 'jump' by a very short distance onto $11 \mathrm{~S}_{(m+h)}$ to reflect the existence of this new segment in the subsequent OxLim analysis. The final 12 coordinates of the margin node, denoted by $\vec{X}_{m a r}$, are determined as

$$
\vec{X}_{m a r}=\vec{X}_{(m+k)}+\zeta \cdot h \cdot\left(\vec{X}_{(m+1+h)}-\vec{X}_{(m+h)}\right)
$$

13 where $\vec{X}_{(m+1+h)}$ and $\vec{X}_{(m+h)}$ are the coordinates of $\mathrm{P}_{(m+1+h)}$ and $\mathrm{P}_{(m+h)}$ at the end of the increment, 14 and $\zeta$ is a fraction parameter, which should be small (relative to 1 ) to avoid spurious modification 15 of the model configuration; for this paper a value of 0.05 is used.

Figure 5 shows a schematic of how this operation is performed, where $h=+1$ is assumed. This 
1 To check whether an arbitrary node, $\mathrm{n}$, is within a convex domain, all $N$ vertices, from $\mathrm{P}_{(0)}$ to $2 \mathrm{P}_{(N-1)}$, of this domain are sorted in counterclockwise order, as illustrated in Figure 6. For each 3 vertex, a vector $\vec{v}_{(j)}$ is then defined as the cross product of the vectors $\mathrm{n} \rightarrow \mathrm{P}_{(j)}$ and $\mathrm{P}_{(j)} \rightarrow \mathrm{P}_{(j+1)}$, 4 which are illustrated in Figure 6. The index $j+1$ should be replaced by 0 when $j=N-1$. Node $\mathrm{n}$ 5 is determined to be within the convex domain if

$$
\operatorname{sign}\left[\vec{v}_{(j)}\right]>0 \quad \forall j \in\{0, \ldots, N-1\}
$$




\subsection{Strain softening and strain rate}

2 A modified Tresca soil model proposed by Einav and Randolph [61] is employed in the SLA

3 simulations to account for the effects of strain softening and strain rate:

$$
s_{u}=s_{u 0} \times\left[\delta_{r e m}+\left(1-\delta_{r e m}\right) e^{-3 \xi / \xi_{95}}\right] \times\left[1+\mu \log _{10}\left(\frac{\max \left(\dot{\gamma}_{,} \dot{\gamma}_{r e f}\right)}{\dot{\gamma}_{r e f}}\right)\right]
$$

4 where $s_{u 0}$ denotes the intact undrained shear strength of the soil, the first bracketed term accounts

5 for softening behaviour as a function of the accumulated plastic shear strain, $\xi$, while the second

6 bracketed term accounts for viscous rate effects as a function of the current maximum shear strain 7 rate, $\dot{\gamma}$, at the material point in question. The softening parameter $\delta_{\text {rem }}$ is the ratio of the fully 8 remoulded shear strength to the initial shear strength of the soil (i.e. the inverse of the sensitivity, $S_{t}$ ).

9 The ductility parameter $\xi_{95}$ corresponds to the plastic shear strain at which the soil has undergone $1095 \%$ of the reduction in strength due to remoulding. For typical soft marine clays, $S_{t}$ ranges from 112 to 5 and $\xi_{95}$ ranges from 10 to 50 [62]. The reference shear strain rate $\dot{\gamma}_{\text {ref }}$ is usually taken as $123 \times 10^{-6} / \mathrm{s}$, approximately $0.01 / \mathrm{h}$ [42]. The viscosity parameter $\mu$ represents the rate of strength 13 increase per decade of strain rate increase, and is typically in the range 0.05 to 0.2 for cohesive soils 
1 the accumulated plastic shear strain at each node is updated as

$$
\xi_{(t+\Delta t)}=\xi_{(t)}+\dot{\gamma} \cdot \Delta t
$$

2 With the variables described above, the operative shear strength at each node of the SLA model

3 can be calculated. A linear variation of strength within each triangular element is obtained by

4 prescribing separate strengths at each vertex. Although second-order triangular elements are used

5 for interpolation of field variables, as described below, the information carried by the mid-side nodes

6 is not used for determining the operative strength distribution, as a quadratic variation of strength

7 within each element is not currently handled by OxLim.

\section{2.3. Remeshing and interpolation}

9 After the model configuration has been updated in each increment, the mesh is checked to see if any

Int. J. Numer. Anal. Meth. Geomech. (2016) 
1 Although the reference plane of $\mathrm{RM}_{(n-2)}$ does not necessarily overlap completely with the target

2 plane of $\mathrm{CM}_{(n)}$, it still provides useful information for most of the nodes. For each field variable, the

3 larger of the two values obtained from $\mathrm{RM}_{(n-2)}$ and $\mathrm{RM}_{(n-1)}$ is chosen. At this stage the values of

4 these attributes for each node do not have to be accurate since they are only providing information

5 for refining the coarse mesh, rather than the actual update of material properties.

6 For an arbitrary triangular element in the coarse mesh, the target area $A_{\text {ref }}$ used to refine this 7 element when generating the new mesh is determined by a heuristic

$$
A_{\text {ref }}=f\left(\xi, \dot{\gamma}, \delta_{\text {rem }}, \xi_{95}, D, A_{\text {min }}\right)
$$

8 where $f$ is a function that varies with the problem investigated and $D$ is a characteristic length such 9 as footing width or pipe diameter. The definition of $f$ ensures that $A_{r e f}$ decreases with $\xi$ as well as 10 with $\dot{\gamma}$, so regions that are severely remoulded or experiencing intense shearing are discretised with a

15 value for $A_{r e f}$ is determined as

$$
A_{r e f}=A_{\min } \cdot \frac{\dot{\gamma}_{0}}{\max \left(\dot{\gamma}, 0.1 s^{-1}\right)}
$$

\section{NUMERICAL EXAMPLES}

This section presents a benchmarking study of the SLA approach. Seven problems with gradually increasing complexity are analysed, as summarised in Table I. These problems are divided into 
1 two categories. The first category (verification) involves four widely studied plane strain plasticity 2 problems that have analytical solutions. These problems are examined to confirm the correct 3 functioning of the SLA method and its implementation, as well as to provide guidance for choosing

4 key parameters (e.g. minimum element $\operatorname{size} A_{\min }$ and incremental displacement $\delta d$ ) in readiness for

5 the study of more complex and realistic problems. The other category (validation) involves three

6 transverse pipe-soil interaction problems with increasingly complicated geometry evolution and

7 non-linear material behaviour, where physical modelling results are available for comparison.

8 In addition to comparisons with available analytical solutions and model test results, the 9 normalised bracketing discrepancy between the LB and UB solutions during the SLA simulations, 10 defined as $(\mathrm{UB}-\mathrm{LB}) /(\mathrm{UB}+\mathrm{LB})$, is presented to further demonstrate the high quality of the results. 11 For all problems that involve the evolution of plastically deforming free surfaces, the total volume 12 of the deforming material is also monitored to check for incompressibility.

13 A detailed comparison of the SLA approach with the CEL analysis capability available in Abaqus 14 [67] has been performed as part of the more extensive verification and validation programme in [66].

Selected CEL results are provided here for comparison, but the numerical details of the CEL models are omitted for the sake of brevity. The reader is referred to [66] for this information.

\subsection{General features of SLA modelling}

Int. J. Numer. Anal. Meth. Geomech. (2016) 
Int. J. Numer. Anal. Meth. Geomech. (2016) 
1 large displacement of the plate. This value is only slightly higher than the analytical solution of

$22+3 \pi=11.42$ derived in [68] for a plate with zero thickness. A rough-sided plate with a thickness

3 of $0.02 D$, as used here, would be expected to yield an additional normalised resistance component

4 of 0.04 , so that the calculated result is very close to the analytical value. The normalised bracketing

5 discrepancy between the LB and UB solutions decreases with mesh refinement as shown in Figure

$610 \mathrm{~b}$, and is limited to about $1.5 \%$ for the mesh with $A_{\min }=0.001 D^{2}$.

7 Figure 11 shows the soil failure mechanisms at the initial and final stages of loading. The

8 shear strain rates $\dot{\gamma}$ are normalised using the plate width $D$ and plate velocity $v_{p}$. The failure

9 mechanisms are found to be identical at the different stages of loading, with the region of intense

10 shearing contained entirely within the finely meshed area throughout the analysis. This confirms the

11 effectiveness of the remeshing strategy described in Section 2.3.

\section{3.3. Vertical loading of a buried pipe}

13 Large vertical displacement of a deeply buried pipe is studied in this section. Analytical solutions for 14 this problem are derived in [3] and [4], giving normalised resistance values of 9.20 (upper bound) for 15 a smooth pipe and 11.94 (exact) for a rough pipe. In the SLA modelling, a rigid pipe cross-section 16 of diameter $D$ was pre-embedded with its invert at a depth of $3 D$ below a fixed surface, and then 17 displaced downwards by $1 D$. The displacement increment $\delta d$ and minimum element size $A_{\min }$ were

Int. J. Numer. Anal. Meth. Geomech. (2016) 
5 In this section, continuous indentation of a smooth wedge into weightless rigid-plastic Tresca

$$
\cos (\beta-\psi)=\frac{\cos \psi}{1+\sin \psi}
$$

Three wedges with apex angles, $\beta$, of $30^{\circ}, 60^{\circ}$ and $90^{\circ}$ were pushed to a final depth, $D$, of $0.5 \mathrm{~m}$. The dimensions $B / 2$ and $h$ of the SLA model (see Figure 9) were $2 \mathrm{~m}$ and $1.5 \mathrm{~m}$ respectively. The shear strength of the soil was taken as $1 \mathrm{kPa}$. The adopted values of $\delta d$ and $A_{\min }$ were $0.01 D$ and $0.001 d^{2}$, the latter meaning that the mesh density varied during the indentation process as the penetration $d$ increased. Adoption of a constant mesh density would have yielded less satisfactory results at very shallow indentation depths, where only a small region of soil is undergoing plastic deformation. A brief parametric study was performed to investigate the influence of $\delta d$ and $A_{\min }$ on the solutions.

Figure 15 shows the SLA load-displacement responses for wedges with different apex angles, together with the theoretical solutions from [69]. There is excellent agreement between the numerical and analytical results. The right side of Figure 14 illustrates the adaptively refined mesh and the distribution of normalised shear strain rate $\dot{\gamma} D / v_{p}$ for the wedge with $\beta=60^{\circ}$ at an indentation of $0.4 \mathrm{~m}$. The SLA results show a rigid block adjacent to the wedge and another at 
Int. J. Numer. Anal. Meth. Geomech. (2016) 
1 The values of $A_{\min }$ and $\delta d$ were chosen to be $0.00025 D^{2}$ and $0.001 D$ following preliminary analyses

Int. J. Numer. Anal. Meth. Geomech. (2016) 
1 SLA. The observed stronger response for CEL is consistent with the failure mechanisms shown

2 in Figure 20c, as the plastic region in the CEL analysis is found to be slightly larger than that

3 in the SLA simulation. The reason why the CEL analysis develops a larger mechanism could

4 possibly be attributed to the incorporation of elastic response, which cannot be captured in SLA.

5 The discretisation error in the relatively coarse CEL mesh could also contribute to this difference.

$6 \quad$ Figure $19 \mathrm{~b}$ shows the normalised change in material volume $\left(\Delta \mathrm{Vol} / \mathrm{D}^{2}\right)$ during the SLA

7 simulations. The volume change is found to increase with the number of incremental analyses in

8 the sequence. This reveals that the remeshing involved in SLA modelling does inevitably introduce

9 some degree of non-physical volume change. However, even for the case with the largest number

10 of increments (and deepest embedment), the normalised volume change is limited to an extremely

11 small value of $4.2 \times 10^{-4}$.

Figure 20 shows the soil failure mechanisms at different stages of the footing penetration. CEL results (left) are provided for comparison with the SLA results (right). Very good agreement is found throughout the loading process, except for the initial stage where a global failure mechanism is not 15 yet fully developed in the CEL model (Figure 20a). A fan region, two rigid blocks and a perimeter 16 slip line embracing the whole mechanism are visible, particularly in the SLA plots, revealing a 17 classical Prandtl-like mechanism. Figure 20 confirms that throughout the loading process, highly 18 refined meshes cover the areas of intense shearing in the SLA model.

Int. J. Numer. Anal. Meth. Geomech. (2016) 
Figure 21 shows the experimental load-penetration curve compared with the results from various simulations. The experimental curve is the average of several model tests, rather than data from a specific test; this averaged curve was the one used in [71] for comparisons with numerical modelling. SLA with non-softening soil moderately overestimates the penetration resistance by about $12 \%$. SLA with softening soil can reasonably predict the loading response, especially at deep embedment, but underestimates the resistance at depths less than $2.5 \mathrm{D}$. A close match with the experimental curve over the whole depth of penetration cannot be achieved by the SLA simulations presented here. Also shown in Figure 21 is the bracketing discrepancy corresponding to the SLA simulation with softening soil. The discrepancy is within about $1.5 \%$ beyond an embedment of $0.5 D$, which represents a high standard of computing accuracy considering that the material has a nonhomogeneous initial strength profile and also undergoes significant strain softening. The normalised volume change of the material, $\Delta \mathrm{Vol} / \mathrm{D}^{2}$, is $2.4 \times 10^{-3}$ at the end of the SLA simulation, indicating a very good approximation of constant-volume deformation.

Considering the uncertainty in quantifying the soil strength in small-scale model tests, in Figure 21 some alternative numerical results from Abaqus CEL modelling [66] are presented for comparison with the SLA data, and very good agreement between the two is observed. Whilst the SLA simulation was performed on a 4-core desktop computer with 4 GB RAM, the CEL analysis was completed on a 32-core cluster with 64 GB RAM. The SLA and CEL computing times for the softening soil case are $13661 \mathrm{~s}$ and $61520 \mathrm{~s}$ respectively, indicating a considerable advantage of SLA in computing efficiency. A fully objective comparison (same computer, similar mesh density, etc.) of computing times between SLA and CEL is very difficult to make, and this issue will be discussed further in Section 4.2.

Figure 22 provides comparisons of the soil failure mechanisms in the SLA and CEL simulations at different embedments. The deformation patterns of the two numerical analyses align very well, particularly given that different algorithms and element types were used. Since the model test was conducted at $1 g$ at a very small scale, the effect of the soil weight was not as significant as it would be for a full-scale pipe in the field. As a result, backfilling of the soil over the pipe is absent in both 
1 the physical modelling and the numerical simulations. Figure 23 shows the softening factor of the 2 soil (the first bracketed term in Equation 10) at the end of loading, and there is good agreement between SLA and CEL. Note that the CEL analyses were performed with a user-defined material

4 subroutine implementing Equation 10. In this subroutine the accumulated plastic shear strain, $\xi$,

5 was updated using the difference between the major and minor principal strain increments. This is 6 to be consistent with the definition used in the SLA formulation (see Section 2.2).

7 3.7. Shallow indentation of a pipe in rate-dependent softening soil

8 In this section, the SLA method is used to simulate a centrifuge model test reported by Dingle et al. 9 [72], where a model pipe segment was penetrated vertically to a depth of $0.45 D$. Key parameters

Int. J. Numer. Anal. Meth. Geomech. (2016) 
Int. J. Numer. Anal. Meth. Geomech. (2016) 
$10.00025 D^{2}$. The pipe displacement increment $\delta d$ was set to $0.0025 D$ and $0.005 D$ for the vertical

2 and lateral loading stages respectively. Tension was not allowed at the interface by default, but one

3 case with unlimited tension was also modelled to study its effect on the initial break-out phase of

4 the lateral loading stage. The interface roughness factor $\alpha$ was set as 0.5 . The pipe was first pushed

5 vertically into the soil to a depth of $0.45 D$, after which it was displaced horizontally for a distance

6 of $3 D$ under a constant vertical load of $3.3 \mathrm{kN} / \mathrm{m}$ (see Table III).

7 Figure 28 shows the centrifuge model test results as well as the numerical results, in terms of the

8 pipe invert trajectory and the lateral load-displacement response. It is observed that when the effects

9 of both strain rate and softening are considered in the SLA modelling, there is good agreement

10 between the experimental and numerical results. The computing time for this SLA simulation was

$1111094 \mathrm{~s}$. The analysis with ideal soil (rate-independent, no softening) largely overestimates the

12 lateral resistance. The analysis with rate-independent softening soil moderately underestimates the

13 resistance at the start of the lateral loading phase, but yields the most satisfactory results near the 
1 to the fact that the soil strength at very shallow depth is likely to be overestimated in the SLA

2 simulation, as a result of using a linear fit to approximate the experimentally measured strength

3 profile. This means that when the surficial soil is scraped by the pipe to form the active berm, the

4 berm will be stronger in the SLA simulation than in the centrifuge test.

5 Figures 30a and 30b show the strength reduction factor due to softening (the first bracketed term

6 in Equation 10) at different stages of lateral loading. It can be seen that the soil within the active

7 berm has become severely softened by the end of loading. Of most importance is that, with six-

8 noded triangular elements being used to perform quadratic interpolation of field variables when

9 the model is remeshed, there is no significant numerically-induced 'pollution' of the field variables.

10 This can be checked by comparison of the softening factor distribution in the left-hand berm, behind

11 the pipe, between Figures 30a and 30b.

Figure 30c shows the strength enhancement factor due to strain rate (the second bracketed term in Equation 10) at the end of loading. The area influenced by the strain rate effect is very localised, though the soil strength within the deforming region is enhanced by about $50 \%$. Figure 30 d shows the combined strength modification factor of the soil, with both strain softening and strain rate effects being taken into account. It can be observed in Figures 30b and 30c that the regions being softened and those being enhanced hardly coincide. Therefore the combined strength modification factor in Figure 30d varies over a very wide range, suggesting that in complex problems such as this, the influences of strain softening and strain rate do not counterbalance, and must be accounted for as separate effects.

\section{DISCUSSION}


1 For instance, in modelling the lateral movement of a rigid body under a constant vertical load (as

described in Section 3.8), the vertical load may be close to the vertical bearing capacity. In moving from one increment to the next, the new vertical bearing capacity may be lower than the vertical load, so that the model collapses without the opportunity for further lateral loading. Such a situation can be detected when the nodal velocities obtained from the UB analysis are unrealistically large (e.g. over $10^{6}$ times the rigid body velocity). Similarly, there may be slope instability issues encountered as a result of an ill-shaped gap or a steep slope (Figure 31), which need to be resolved in order for the analysis sequence to continue. These difficulties are particularly relevant to the large-displacement problems explored in Sections 3.6 and 3.8.

The approach used in the present SLA simulations is that once a collapse situation is detected, the rigid body is temporarily forced to move under pure displacement control, if applicable. For example, in the lateral loading of a pipe under constant vertical load, the downward velocity can be temporarily set as some fraction (e.g. 20\%) of the lateral velocity. If the instability cannot be resolved in this way, the controlling code then checks to see if there are stability problems caused by an ill-shaped gap or a steep slope.

To deal with an ill-shaped gap (Figure 31a), a critical surface node must be found. The criterion to determine such a node $\mathrm{n}_{(p)}$ is that its horizontal coordinate should be closer to the rigid body centre than two adjacent nodes, $\mathrm{n}_{(p-1)}$ and $\mathrm{n}_{(p+1)}$. The vertical coordinate of such a node should also be lower than the centre of the rigid body, otherwise, a node such as $\mathrm{n}_{(q)}$ in Figure 31a will be mistakenly recognised to form a 'gap'. Node $\mathrm{n}_{(p)}$ is then removed from the list of free surface nodes. A new model is then generated based on the reconstructed surface. This process is repeated until the slope instability issue has been resolved or a critical surface node cannot be found.

To handle collapse of a steep slope above the crown of a deeply penetrated rigid body (Figure 31b), an auxiliary domain slightly larger than the rigid body but of exactly the same shape is established. All surface nodes are checked to see if they can be located within this domain. If such a node is found (see $\mathrm{n}_{(p-2)}, \mathrm{n}_{(p-1)}$ and $\mathrm{n}_{(p)}$ in Figure $31 \mathrm{~b}$ ), it is projected perpendicularly onto the nearest rigid body segment in an attempt to restore the slope stability. Of all the nodes that meet the 
1 elements). Moreover, whilst the SLA analyses were performed on a desktop computer with 4 cores 2 and 4 GB RAM, most of the CEL analyses could only be carried out on a cluster with 16 to 32 cores 3 and 64 GB RAM. The different element types (2D second-order triangle for SLA and 3D first-order

4 brick for CEL) also contribute to the difficulty of making such a comparison. However, the focus of

5 Table V is to demonstrate that numerical modelling using SLA is very efficient in absolute terms,

6 rather than more efficient by comparison with other particular methods such as CEL analysis.

7 One reason for the efficiency of SLA lies in the fact that it avoids the need to keep track of 8 stresses at integration points, for use in elastic-plastic constitutive equations [24]. As a consequence,

9 SLA can generate reliable results using relatively coarse meshes for each individual FELA solution 10 in the sequence, and for the interpolation of field variables. More importantly, as tested in the 11 benchmark studies, reliable geometric updating can be achieved in SLA even when using large 12 incremental displacements $(0.002 D$ to $0.005 D)$. These are significantly greater than the incremental displacements used in the complementary CEL analyses (automatically chosen by Abaqus but 14 typically of order $10^{-5} D$ ). This means that the same problem can be completed with fewer increments in SLA than in CEL or in other FE methods.

\section{CONCLUSIONS}

Int. J. Numer. Anal. Meth. Geomech. (2016) 
1 of stresses is needed during the interpolation stage, which is beneficial for numerical stability and

2 computing efficiency.

3 The treatment of evolving interfaces and boundaries in SLA modelling inevitably introduces some

4 spurious volume change for the (assumed) incompressible rigid-plastic material. However, for all of

5 the problems investigated in this paper, the cumulative volume change was found to be very limited

6 by comparison with the volume of the rigid body driving the process (ratio of order $10^{-3}$ or less),

7 and therefore unlikely to influence the overall model response.

8 A detailed verification and validation study has been presented, using both analytical plasticity 9 solutions and physical model test results. Excellent agreement was found between SLA simulation 10 results and theoretical solutions from slip-line theory, indicating that the approach is robust. When 11 taking into account the effects of strain softening and strain rate on the undrained shear strength 12 of the soil, the SLA approach was able to generate very satisfactory predictions of both $1 g$ 13 and centrifuge model tests on pipeline segments causing large plastic deformations of soft clay 14 specimens.

Possible areas for future work include extension of the present SLA approach to axially symmetric and three-dimensional problems, and to situations where collapse of the soil is driven by gravity rather than by a rigid body. The use of mesh-free methods to obtain (non-strict) upper bound limit analysis solutions (e.g. [74, 75]) could also be worth exploring in the context of SLA.

\section{REFERENCES}

1. Gvozdev AA. The determination of the value of the collapse load for statically indeterminate systems undergoing plastic deformation. International Journal of Mechanical Sciences 1960; 1(4):322-335.

2. Drucker DC, Prager W, Greenberg HJ. Extended limit design theorems for continuous media. Quarterly of Applied Mathematics 1952; 9:381-389.

3. Randolph MF, Houlsby GT. The limiting pressure on a circular pile loaded laterally in cohesive soil. Géotechnique 1984; 34(4):613-623.

4. Martin CM, Randolph MF. Upper bound analysis of lateral pile capacity in cohesive soil. Géotechnique 2006; 56(2):141-145. 
5. Randolph MF, Martin CM, Hu Y. Limiting resistance of a spherical penetrometer in cohesive material. Géotechnique 2000; 50(5):573-582.

6. Martin CM. Vertical bearing capacity of skirted circular foundations on Tresca soil. Proc. 15th Int. Conf. on Soil Mechanics and Geotechnical Engineering, Istanbul, 2001; 743-746.

7. Lysmer J. Limit analysis of plane problems in soil mechanics. Journal of the Soil Mechanics and Foundations Division (ASCE) 1970; 96:1311-1334.

8. Anderheggen E, Knöpfel H. Finite element limit analysis using linear programming. International Journal of Solids and Structures 1972; 8:1413-1431.

9. Pastor J. Analyse limite: détermination numérique de solutions statiques complètes. application au talus vertical. Journal de Mécanique Appliquée 1978; 2:167-196.

10. Sloan SW. Lower bound limit analysis using finite elements and linear programming. International Journal for Numerical and Analytical Methods in Geomechanics 1988; 12(1):61-77.

11. Sloan SW, Kleeman PW. Upper bound limit analysis using discontinuous velocity fields. Computer Methods in Applied Mechanics and Engineering 1995; 127(1-4):293-314.

12. Gao Y. Panpenalty finite element programming for plastic limit analysis. Computers and Structures $1988 ; 28: 749$ 755.

13. Zouain N, Herskovits J, Borges L, Feijóo R. An iterative algorithm for limit analysis with nonlinear yield functions. International Journal of Solids and Structures 1993; 30:1397-1417.

14. Borges L, Zouain N, Huespe A. A nonlinear optimization procedure for limit analysis. European Journal of Mechanics A/Solids 1996; 15:487-512.

15. Andersen KD, Christiansen E, Overton ML. Computing limit loads by minimizing a sum of norms. SIAM Journal on Scientific Computing 1998; 19(3):1046-1062.

16. Lyamin AV, Sloan SW. Lower bound limit analysis using non-linear programming. International Journal for Numerical Methods in Engineering 2002; 55:573-611.

17. Lyamin AV, Sloan SW. Upper bound limit analysis using linear finite elements and non-linear programming. International Journal for Numerical and Analytical Methods in Geomechanics 2002; 26:181-216.

18. Makrodimopoulos A, Martin CM. Lower bound limit analysis of cohesive-frictional materials using second-order cone programming. International Journal for Numerical Methods in Engineering 2006; 66(4):604-634.

19. Makrodimopoulos A, Martin CM. Upper bound limit analysis using simplex strain elements and second-order cone programming. International Journal for Numerical and Analytical Methods in Geomechanics 2007; 31:835-865.

20. Krabbenhoft K, Lyamin AV, Sloan SW. Formulation and solution of some plasticity problems as conic programs. International Journal of Solids and Structures 2007; 44(5):1533-1549.

21. Makrodimopoulos A, Martin CM. Upper bound limit analysis using discontinuous quadratic displacement fields. Communications in Numerical Methods in Engineering 2008; 24:911-927.

22. Martin CM, Makrodimopoulos A. Finite-element limit analysis of Mohr-Coulomb materials in 3D using semidefinite programming. Journal of Engineering Mechanics 2008; 134(4):339-347. 
23. Pastor F, Loute E, Pastor J, Trillat M. Mixed method and convex optimization for limit analysis of homogeneous Gurson materials: a kinematical approach. European Journal of Mechanics A/Solids 2009; 28(1):25-35.

24. Yang WH. Large deformation of structures by sequential limit analysis. International Journal of Solids and Structures 1993; 30(7):1001-1013.

25. Hwan CL. An upper bound finite element procedure for solving large plane strain deformation. International Journal for Numerical Methods in Engineering 1997; 40:1909-1922.

26. Raithatha A, Duncan SR. Rigid plastic model of incremental sheet deformation using second-order cone programming. International Journal for Numerical Methods in Engineering 2008; 78:955-979.

27. Martin CM. The use of adaptive finite-element limit analysis to reveal slip-line fields. Géotechnique Letters 2011; 1:23-29.

28. Shewchuk JR. Delaunay refinement algorithms for triangular mesh generation. Computational Geometry 2002; 47:741-778

29. Ayachit U. The ParaView Guide: A Parallel Visualization Application. Kitware Inc., 2015.

30. MOSEK ApS. The MOSEK optimization tools manual, Version 7. 2013.

31. Burgess D, Sulsky D, Brackbill JU. Mass matrix formulation of the FLIP particle-in-cell method. Journal of Computational Physics 1992; 103:1-15.

32. Sulsky D, Chen Z, Schreyer HL. A particle method for history-dependent materials. Computer Methods in Applied Mechanics and Engineering 1994; 118:179-196.

33. Zhou SJ. The numerical prediction of material failure based on the material point method. PhD Thesis, University of New Mexico 1998.

34. Coetzee CJ, Vermeer PA, Basson AH. The modelling of anchors using the material point method. International Journal for Numerical and Analytical Methods in Geomechanics 2005; 29:879-895.

35. Gingold RA, Monaghan JJ. Smoothed particle hydrodynamics: theory and application to non-spherical stars. Monthly Notices of the Royal Astronomical Society 1977; 181:375-389.

36. Monaghan JJ. Smoothed particle hydrodynamics. Annual Review of Astronomy and Astrophysics 1992; 30:543-574.

37. Benz W, Asphaug E. Simulations of brittle solids using smoothed particle hydrodynamics. Computer Physics Communications 1995; 87(1-2):253-265.

38. Bonet J, Lok TSL. Variational and momentum preservation aspects of smooth particle hydrodynamic formulations. Computer Methods in Applied Mechanics and Engineering 1999; 180(1-2):97-115.

39. Cundall PA. A computer model for simulating progressive, large-scale movements in blocky rock systems. International Symposium on Rock Fracture, Nancy, France, 1971; Paper No. II-8.

40. Cundall PA, Strack ODL. A discrete numerical model for granular assemblies. Géotechnique 1979; 29(1):47-65.

41. O'Sullivan C. The application of discrete element modelling to finite deformation problems in geomechanics. $\mathrm{PhD}$ Thesis, University of California 2002.

42. Zhou H, Randolph MF. Computational techniques and shear band development for cylindrical and spherical penetrometers in strain-softening clay. International Journal of Geomechanics 2007; 7(4):287-295. 
43. Zdravkovic L, Carter J. Contributions to Géotechnique 1948-2008: Constitutive and numerical modelling. Géotechnique 2008; 58(5):405-412.

44. Macaro G. Distinct element modelling of pipe-soil interaction for offshore pipelines on granular soils. DPhil thesis, University of Oxford 2015.

45. Hesar M. Pipeline-seabed interaction in soft clay. Proc. 23rd Int. Conf. on Offshore Mechanics and Arctic Engineering, Vancouver, 2004; Paper No. OMAE2004-51 425.

46. Konuk I, Yu S. Continuum FE modelling of lateral buckling: study of soil effects. Proc. 26th Int. Conf. on Offshore Mechanics and Arctic Engineering, San Diego, 2007; Paper No. OMAE2007-29376.

47. Hu Y, Randolph MF. A practical numerical approach for large deformation problems in soil. International Journal for Numerical and Analytical Methods in Geomechanics 1998; 22:327-350.

48. Wang D, White DJ, Randolph MF. Large-deformation finite element analysis of pipe penetration and largeamplitude lateral displacement. Canadian Geotechnical Journal 2009; 47:842-856.

49. Chatterjee S, Randolph MF, White DJ. The effects of penetration rate and strain softening on the vertical penetration resistance of seabed pipelines. Géotechnique 2012; 62(7):573-582.

50. Chatterjee S, White DJ, Randolph MF. Numerical simulations of pipe-soil interaction during large lateral movements on clay. Géotechnique 2012; 62(8):693-705.

51. Abadalla B, Pike K, Eltaher A, Jukes P, Duron B. Development and validation of a coupled Eulerian Lagrangian finite element ice scour model. Proc. 28th Int. Conf. on Ocean, Offshore and Arctic Engineering, Honolulu, 2009; Paper No. OMAE2009-79553.

52. Qiu G, Grabe J. Explicit modeling of cone and strip footing penetration under drained and undrained conditions using a visco-hypoplastic model. Geotechnik 2011; 34:205-217.

53. Zheng J, Hossain M, Wang D. 3D large deformation FE analysis of spudcan foundation on layered clays using CEL approach. 2nd Int. Symp. on Constitutive Modeling of Geomaterials, International Society of Offshore and Polar Engineers: Anchorage, Alaska, 2012; 803-810.

54. Tho KK, Leung CF, Chow YK, Somsak S. Eulerian finite element simulation of spudcan-pile interaction. Canadian Geotechnical Journal 2013; 50(6):595-608.

55. Andresen L, Khoa HDV. LDFE analysis of installation effects for offshore anchors and foundations. Installation Effects in Geotechnical Engineering, Taylor \& Francis Group: London, 2013.

56. Martin CM, Kong D, Byrne BW. 3D analysis of transverse pipe-soil interaction using 2D soil slices. Géotechnique Letters 2013; 3(3):119-123.

57. Hawlader B, Dutta S, Fouzder A, Zakeri A. Penetration of steel catenary riser in soft clay seabed: Finite-element and finite-volume methods. International Journal of Geomechanics 2015; 15(6).

58. Dutta S, Hawlader B, Phillips R. Finite element modeling of partially embedded pipelines in clay seabed using Coupled Eulerian-Lagrangian method. Canadian Geotechnical Journal 2015; 52:58-72.

59. Klar A, Osman AS, Bolton M. 2D and 3D upper bound solutions for tunnel excavation using 'elastic' flow fields. International Journal for Numerical and Analytical Methods in Geomechanics 2007; 31(12):1367-1374. 
60. Mollon G, Dias D, Soubra AH. Continuous velocity fields for collapse and blowout of a pressurized tunnel face in purely cohesive soil. International Journal for Numerical and Analytical Methods in Geomechanics 2013; 37(13):2061-2083.

61. Einav I, Randolph MF. Combining upper bound and strain path methods for evaluating penetration resistance. International Journal for Numerical Methods in Engineering 2005; 63(14):1991-2016.

62. Randolph MF. Characterization of soft sediments for offshore applications. Proc. 2nd Int. Conf. on Site Characterization, Porto, Portugal, 2004; 209-231.

63. Biscontin G, Pestana JM. Influence of peripheral velocity on vane shear strength of an artificial clay. Geotechnical Testing Journal 2001; 24(4):423-429.

64. Lunne T, Andersen KH. Soft clay shear strength parameters for deepwater geotechnical design. Proc. 6th Int. Offshore Site Investigation and Geotechnics Conf., vol. 1, London, 2007; 151-176.

65. TECPLOT. Version 5 users manual. Amtec Engineering, 1992.

66. Kong D. Large displacement numerical analysis of offshore pipe-soil interaction on clay. DPhil thesis, University of Oxford 2015.

67. Dassault Systémes. Abaqus analysis users manual (6.11). Simula Corp, Providence, RI, USA, 2011.

68. Rowe RK, Davis EH. The behaviour of anchor plates in clay. Géotechnique 1982; 32(1):9-23.

69. Hill R, Lee EH, Tupper SJ. The theory of wedge indentation of ductile materials. Proceedings of the Royal Society A 1947; 188:273-289.

70. Prandtl L. Über die Eindringungsfestigkeit Plastischer Baustoffe und die Festigkeit von Schneiden. Z. Angew. Math. Mech 1921; 1:15-20.

71. Lee YS. Physical and numerical modelling of pipe-soil interaction in clay. PhD Thesis, University of Sheffield 2012.

72. Dingle HRC, White DJ, Gaudin C. Mechanisms of pipe embedment and lateral breakout on soft clay. Canadian Geotechnical Journal 2008; 45:636-652.

73. Wang D, Hu Y, Randolph MF. Three-dimensional large deformation finite-element analysis of plate anchors in uniform clay. Journal of Geotechnical and Geoenvironmental Engineering 2010; 136(2):355-365.

74. Liu F, Zhao J. Upper bound limit analysis using radial point interpolation meshless method and nonlinear programming. International Journal of Mechanical Sciences 2013; 70:26-38.

75. Binesh SM, Raei S. Upper bound limit analysis of cohesive soils using mesh-free method. Geomechanics and Geoengineering 2014; 9(4):265-278. 
Table I. Summary of numerical examples

\begin{tabular}{l|l|c|c|c}
\hline Problem & Compared with & Free surface & Strain softening & Strain rate \\
\hline Buried plate & Analytical [68] & - & - & - \\
\hline Buried pipe & Analytical [3, 4] & - & - & - \\
\hline Wedge & Analytical [69] & $\sqrt{ }$ & - & - \\
\hline Strip footing & Analytical [70]; CEL [66] & $\sqrt{ }$ & - & - \\
\hline Pipe (deep penetration) & $1 g$ model test [71]; CEL [66] & $\sqrt{ }$ & $\sqrt{ }$ & - \\
\hline Pipe (shallow penetration) & Centrifuge test [72]; CEL [66] & $\sqrt{ }$ & $\sqrt{ }$ & $\sqrt{ }$ \\
\hline Pipe (lateral loading) & Centrifuge test [72] & $\sqrt{ }$ & $\sqrt{ }$ & $\sqrt{ }$ \\
\hline
\end{tabular}

Table II. $1 g$ model test parameters from [71]

\begin{tabular}{l|l}
\hline Parameter & Value \\
\hline Pipe diameter, $D: \mathrm{m}$ & 0.03 \\
Shear strength of soil at mudline, $s_{u m}: \mathrm{kPa}$ & 1.1 \\
Shear strength gradient, $\rho: \mathrm{kPa} / \mathrm{m}$ & 4.5 \\
Submerged unit weight of soil, $\gamma^{\prime}: \mathrm{kN} / \mathrm{m}^{3}$ & 6 \\
Final pipe embedment, $w_{\text {fin }}$ & $7 D$ \\
Vertical penetration rate, $v_{p}$ & $0.1 D / \mathrm{s}$ \\
Pipe-soil interface roughness factor, $\alpha$ & 0 \\
Sensitivity of soil, $S_{t}$ & 1.7 \\
Ductility parameter of soil, $\xi_{95}$ & 10 \\
\hline
\end{tabular}


Table III. Centrifuge model test parameters (prototype scale) from [72]

\begin{tabular}{l|l}
\hline Parameter & Value \\
\hline Pipe diameter, $D: \mathrm{m}$ & 0.8 \\
Shear strength of soil at mudline, $s_{u m}: \mathrm{kPa}$ & 2.3 \\
Shear strength gradient, $\rho: \mathrm{kPa} / \mathrm{m}$ & 3.6 \\
Submerged unit weight of soil, $\gamma^{\prime}: \mathrm{kN} / \mathrm{m}^{3}$ & 6.5 \\
Initial pipe embedment, $w_{\text {ini }}$ & $0.45 D$ \\
Final lateral displacement, $u_{f i n}$ & $3 D$ \\
Pipe weight during lateral displacement, $W: \mathrm{kN} / \mathrm{m}$ & 3.3 \\
Vertical penetration rate, $v_{p}$ & $0.015 D / \mathrm{s}$ \\
Lateral displacement rate, $v_{p}$ & $0.050 D / \mathrm{s}$ \\
\hline
\end{tabular}

Table IV. Soil modelling parameters from [73] and [49]

\begin{tabular}{l|l}
\hline Parameter & Value \\
\hline Rate of strength increase per decade, $\mu$ & 0.1 \\
Reference shear strain rate, $\dot{\gamma}_{r e f}: \mathrm{s}^{-1}$ & $3 \times 10^{-6}$ \\
Sensitivity, $S_{t}$ & 3.2 \\
Ductility parameter, $\xi_{95}$ & 10 \\
\hline
\end{tabular}

Table V. Computational times of SLA simulations

\begin{tabular}{l|l|l}
\hline Problem & Total displacement & Time: s \\
\hline Buried plate & $1 D$ & 3248 \\
\hline Buried pipe & $1 D$ & 849 \\
\hline Wedge & $0.5 \mathrm{~m}$ & 1399 \\
\hline Strip footing & $0.5 D$ & 1970 \\
\hline Pipe (deep penetration) & $4 D$ & 13661 \\
\hline Pipe (shallow penetration) & $0.45 D$ & 780 \\
\hline Pipe (lateral loading) & $3.45 D$ & 11094 \\
\hline
\end{tabular}




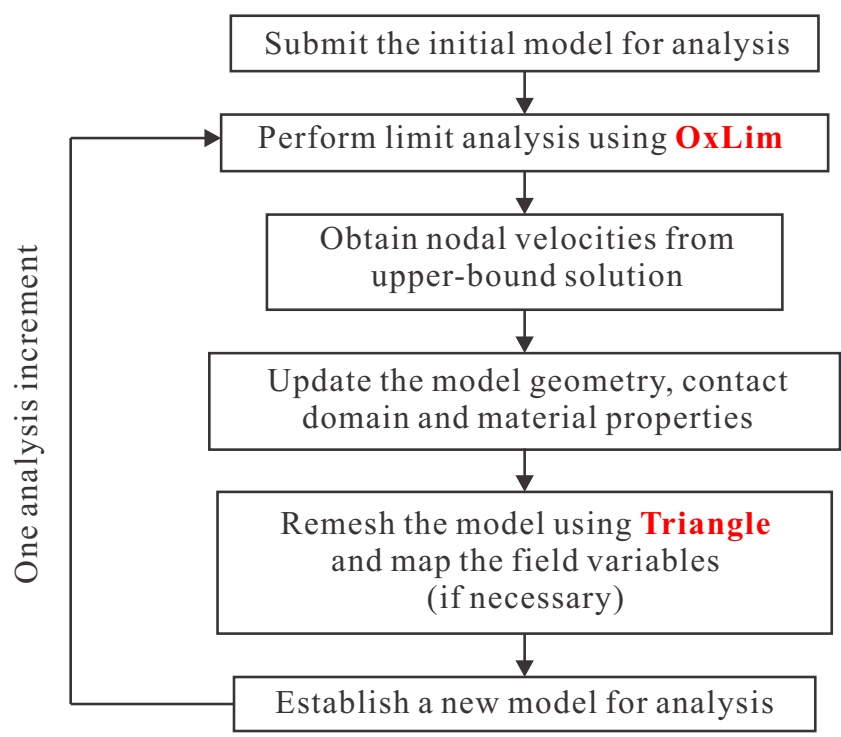

Figure 1. Overall scheme of the SLA approach.

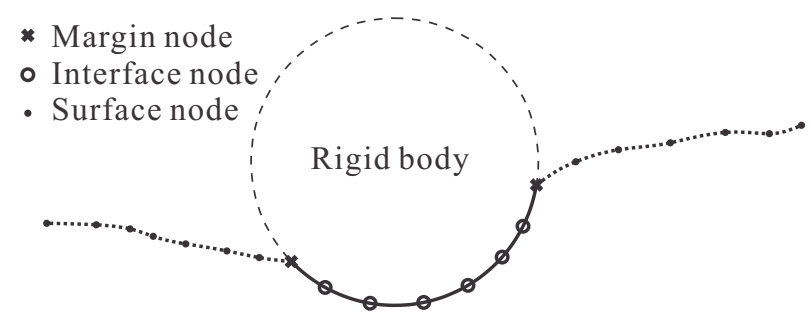

Figure 2. External boundary nodes.

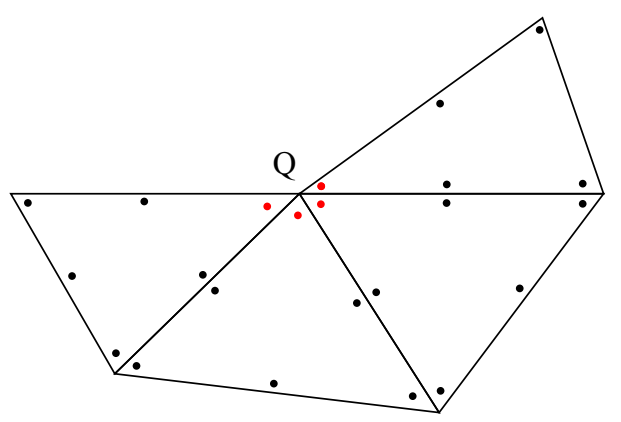

(a)

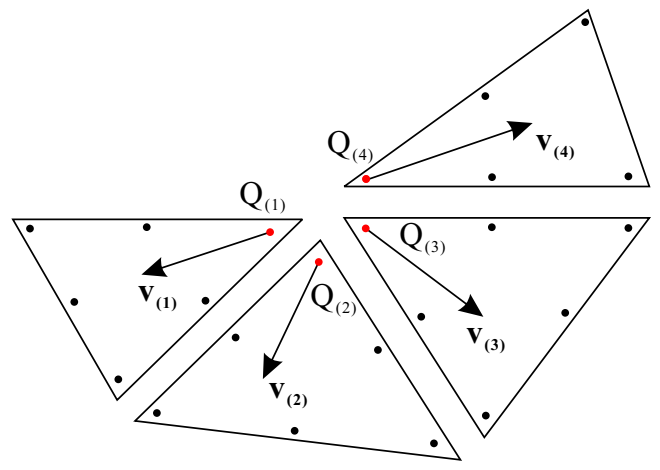

(b)

Figure 3. Nodal velocities in OxLim UB analysis: (a) evaluation points associated with node Q; (b) different velocity vectors of evaluation points (with exaggerated discrepancy). 


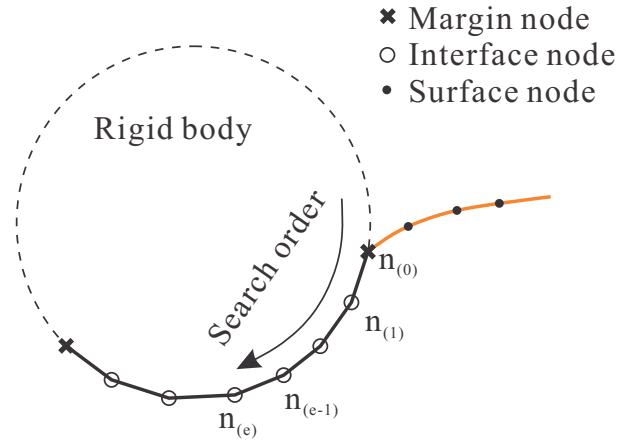

(a)

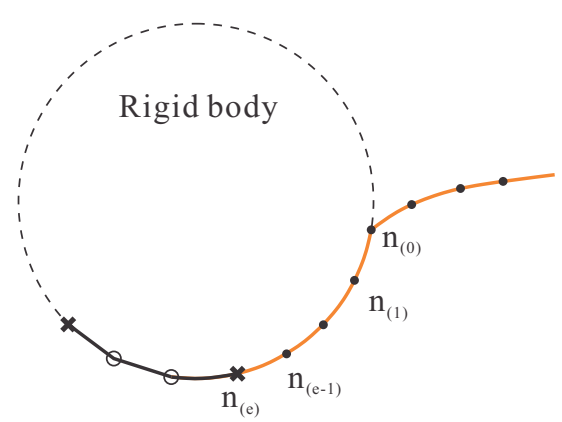

(b)

Figure 4. Interface nodes breaking away from a rigid body: (a) before break; (b) after break. Only the breakaway of the right margin node is shown.

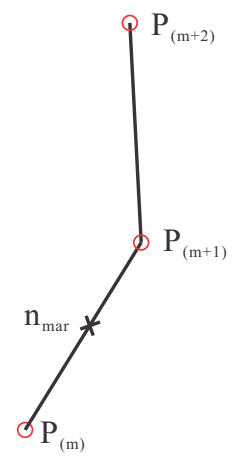

(a)

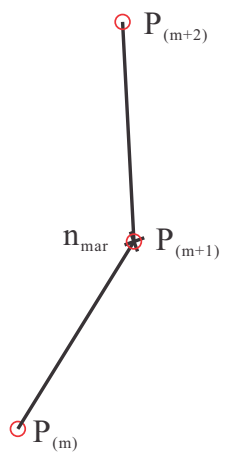

(b)

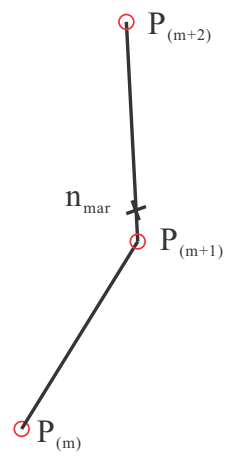

(c)

Figure 5. Schematic of 'jump' of a margin node: (a) before coordinate update; (b) time increment chosen to produce overlap after coordinate update; (c) margin node forced to 'jump' onto next rigid body segment.

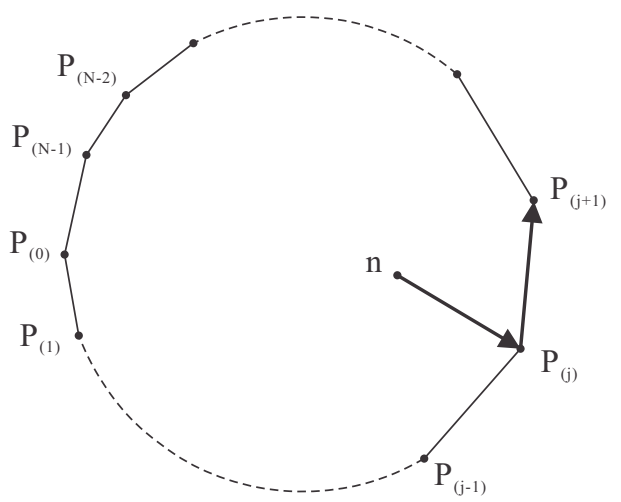

Figure 6. Determining if a point is inside a convex domain. 


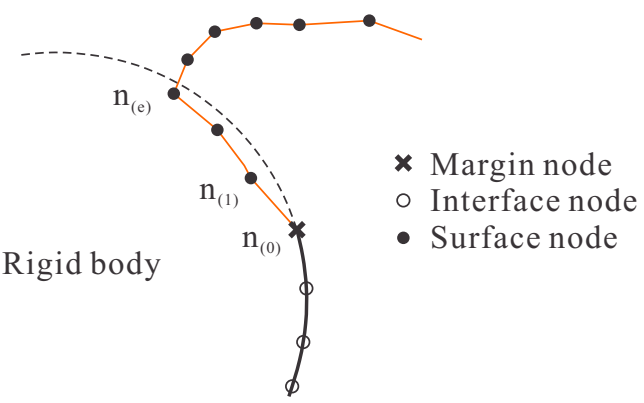

(a)

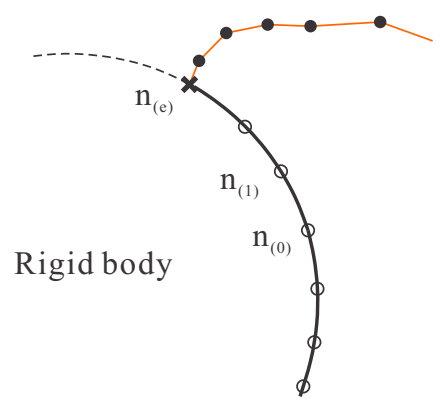

(b)

Figure 7. Handling of nodes that penetrate into a rigid body: (a) before treatment; (b) after treatment.

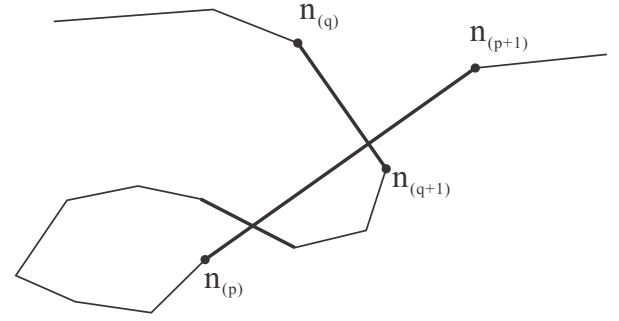

(a)

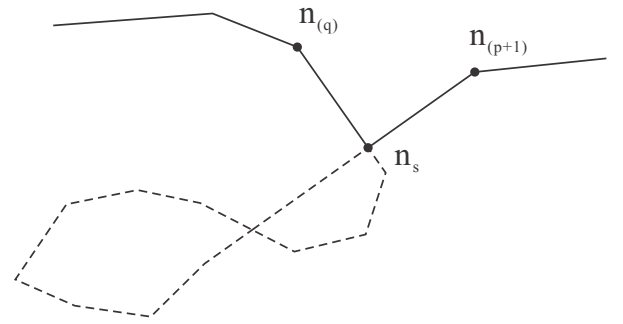

(b)

Figure 8. Handling self-contact of a free surface: (a) nodes encroaching into the surface; (b) reconstruction of the surface.

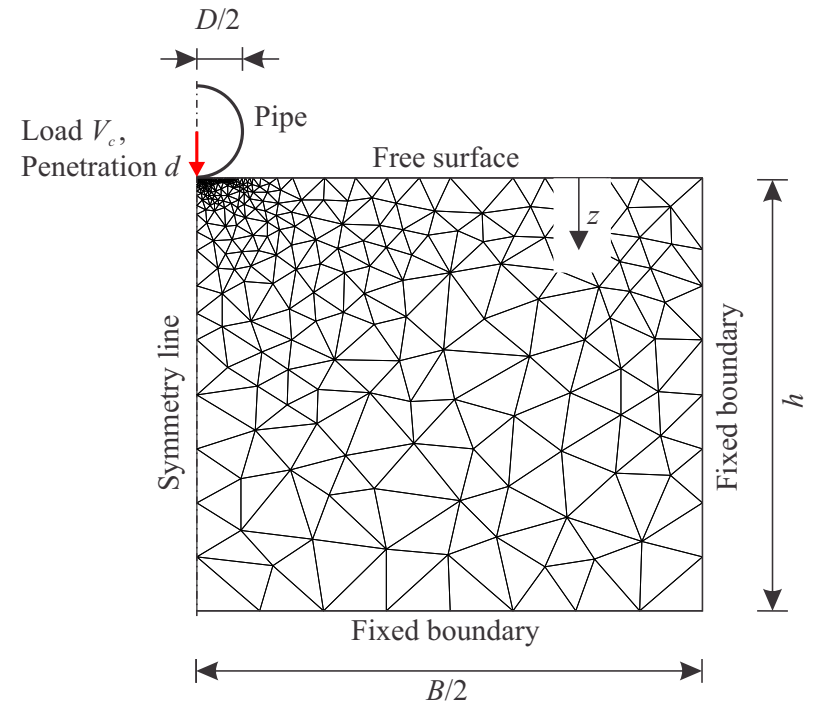

(a)
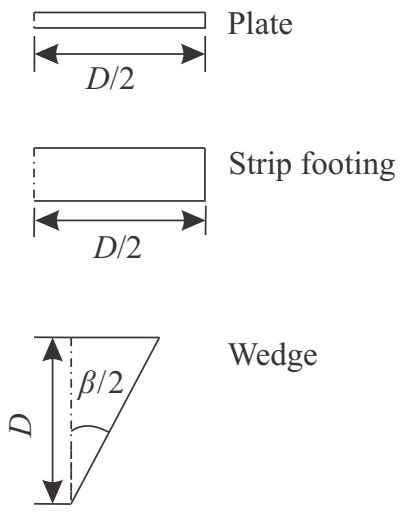

(b)

Figure 9. Initial configuration of SLA model for continuous indentation of a rigid body: (a) penetration of a pipe; (b) other rigid bodies. 


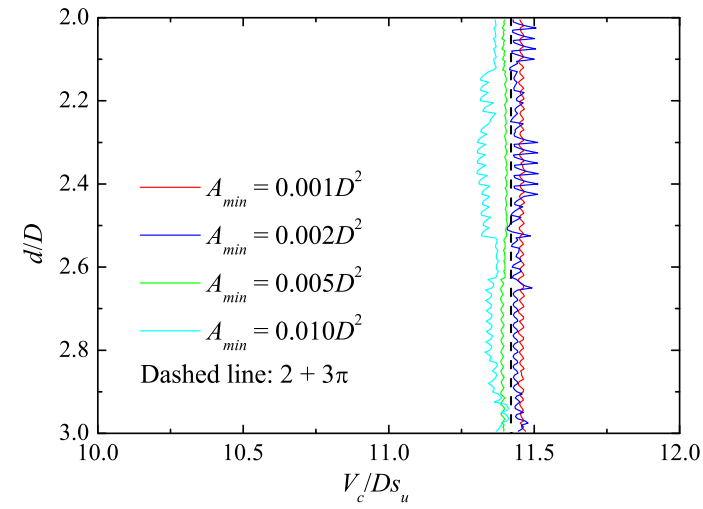

(a)

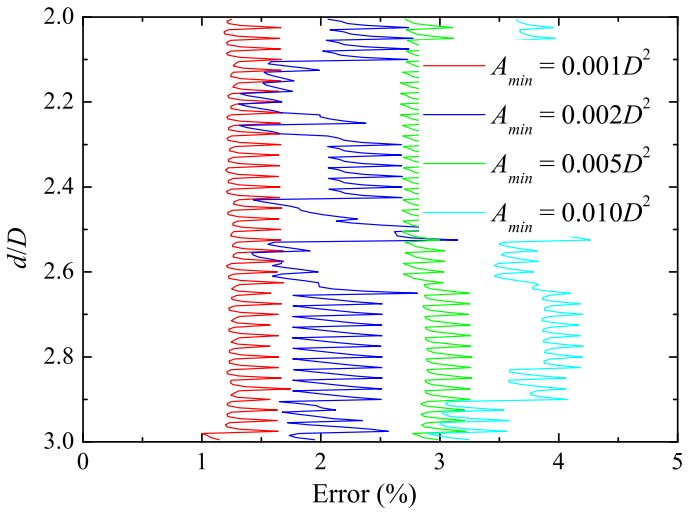

(b)

Figure 10. Vertical loading response of buried plate: (a) normalised resistance; (b) normalised bracketing discrepancy.

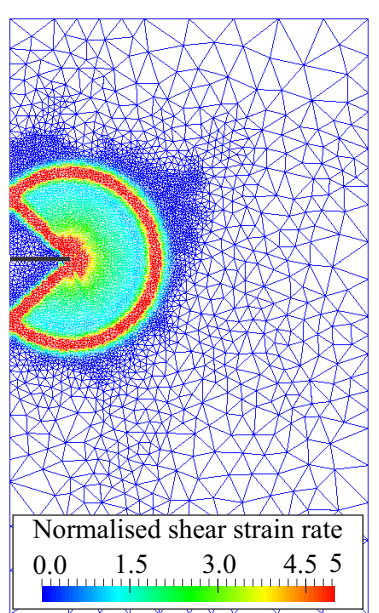

(a)

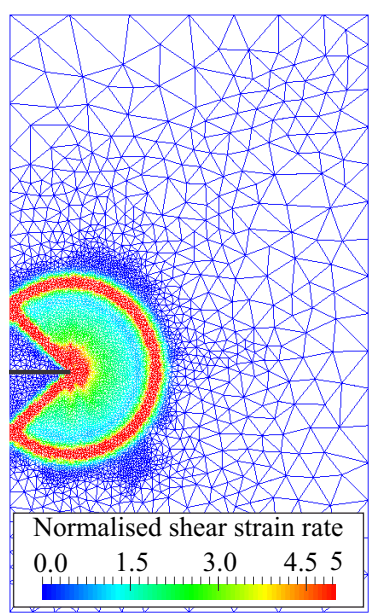

(b)

Figure 11. Soil failure mechanisms (contours of $\dot{\gamma} D / v_{p}$ ) for buried plate: (a) initial, $d / D=2$; (b) final,

$$
d / D=3 .
$$




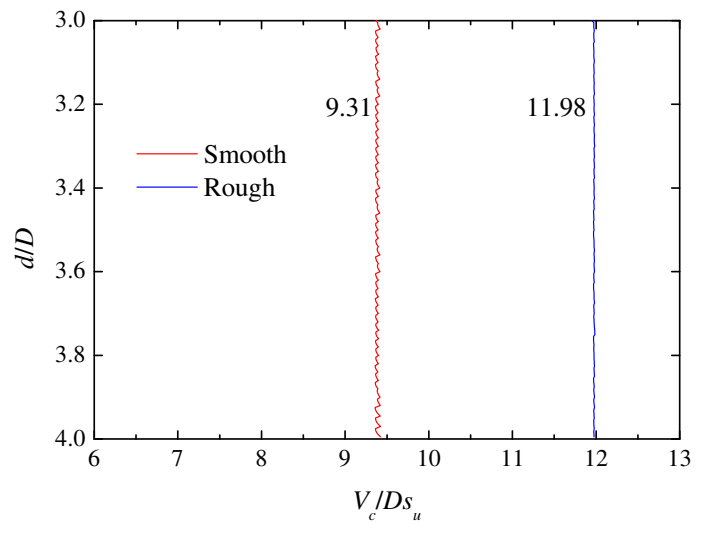

(a)

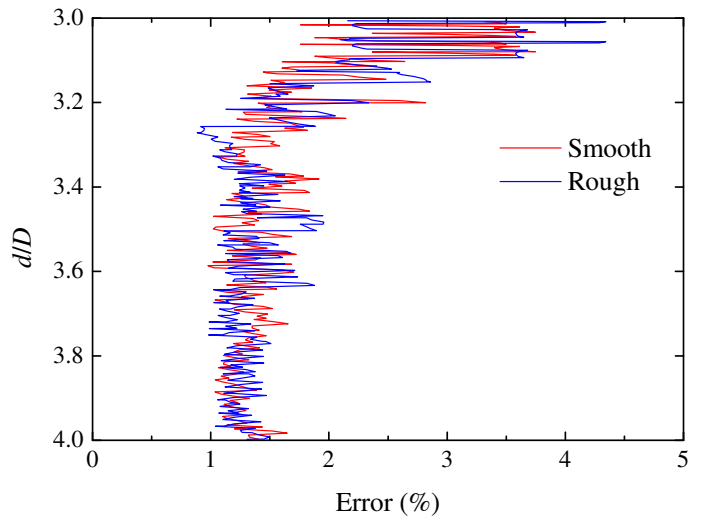

(b)

Figure 12. Vertical loading response of buried pipe: (a) normalised resistance; (b) normalised bracketing discrepancy.

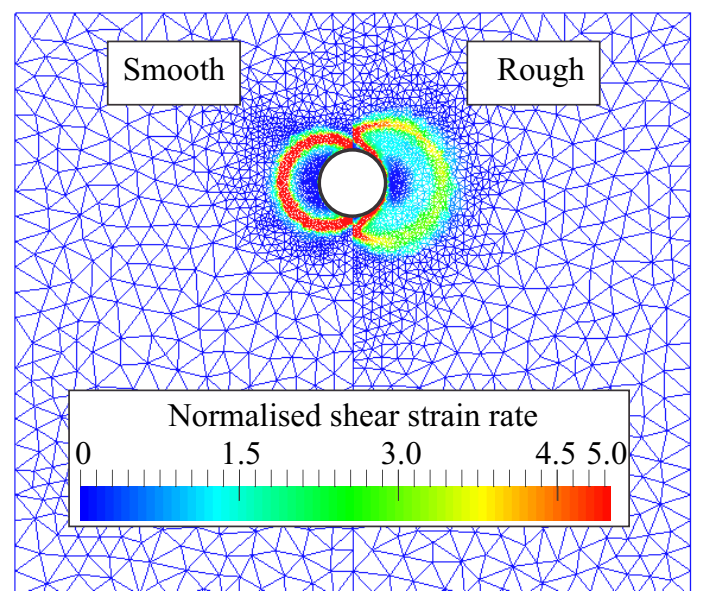

(a)

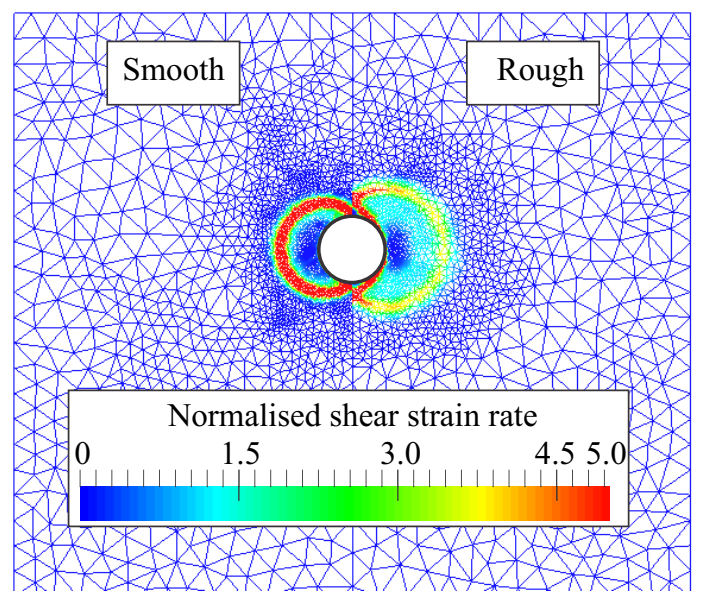

(b)

Figure 13. Soil failure mechanisms (contours of $\dot{\gamma} D / v_{p}$ ) for buried pipe: (a) initial, $d / D=3$; (b) final,

$$
d / D=4
$$




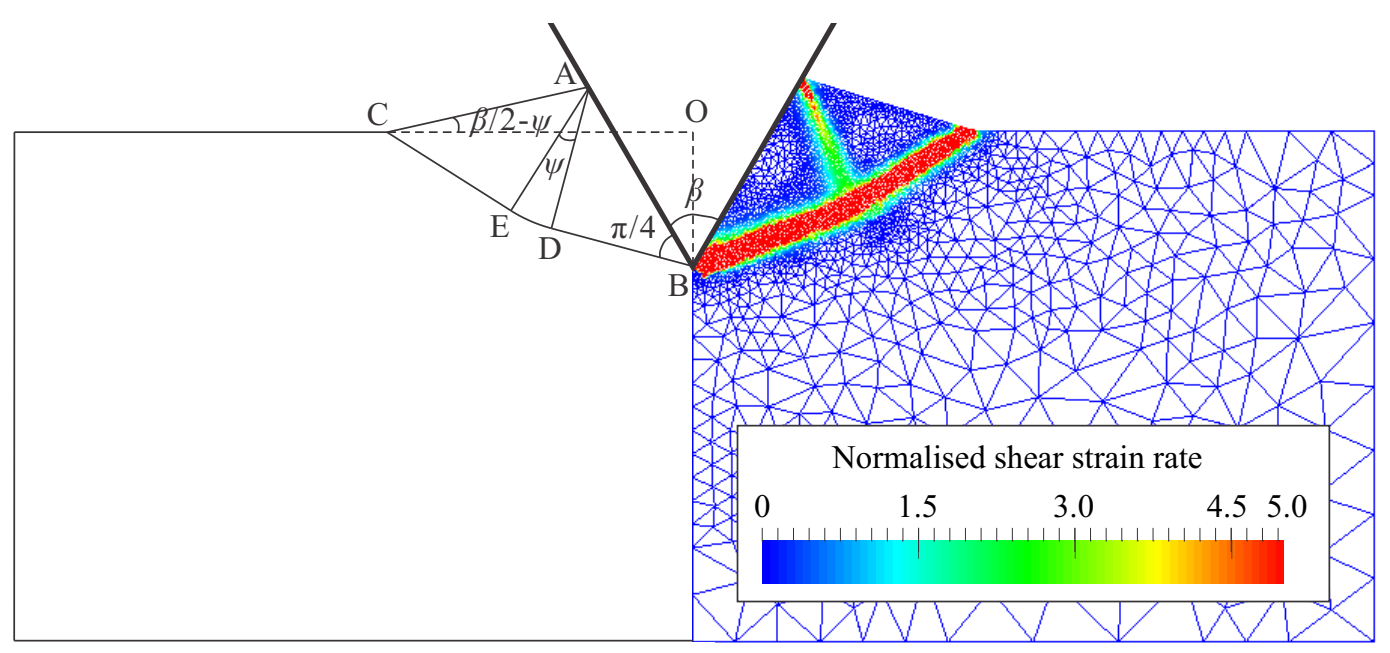

Figure 14. Soil failure mechanisms (contours of $\dot{\gamma} D / v_{p}$ ) for wedge. $\beta=60^{\circ}, d=0.4 \mathrm{~m}$.

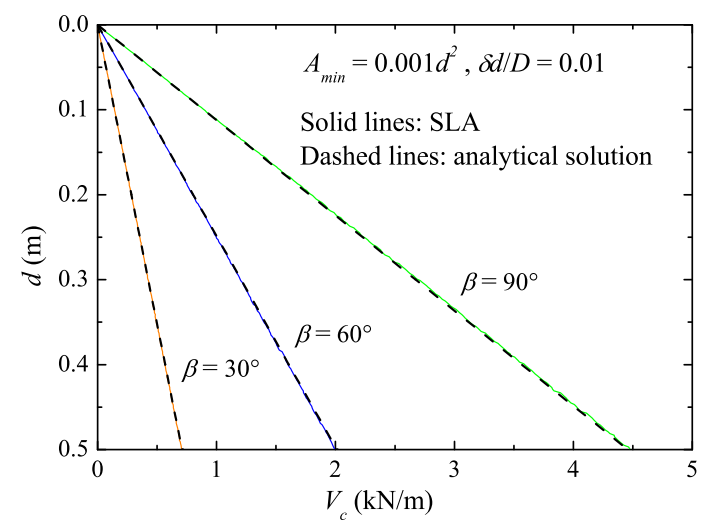

Figure 15. Indentation resistance for different wedge angles.

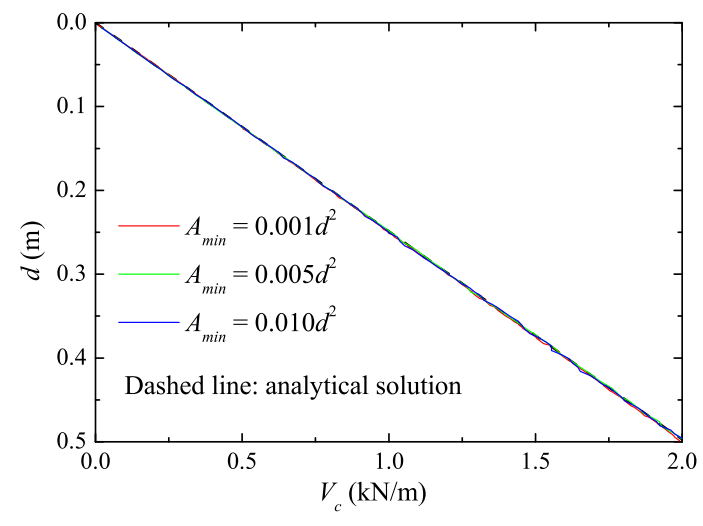

(a)

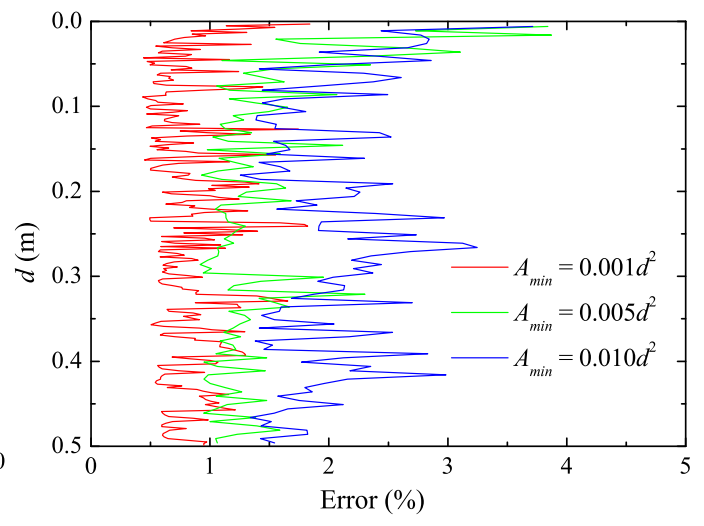

(b)

Figure 16. Influence of minimum element size $A_{\min }$ on wedge indentation response: (a) resistance; (b) normalised bracketing discrepancy. $\beta=60^{\circ}$ and $\delta d / D=0.01$. 


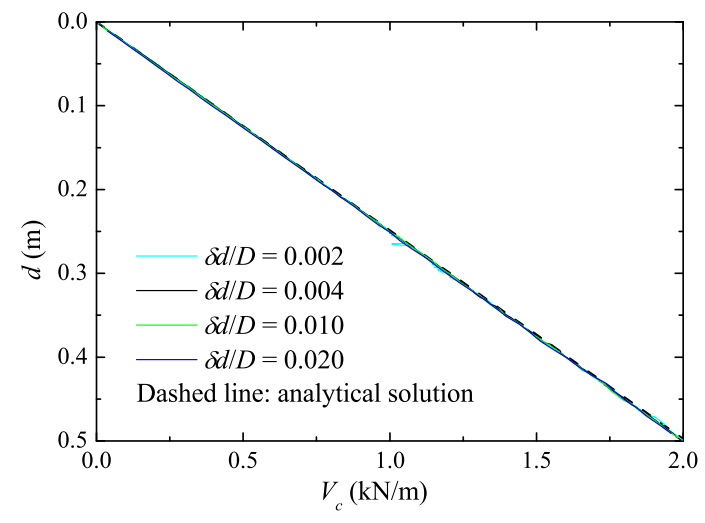

(a)

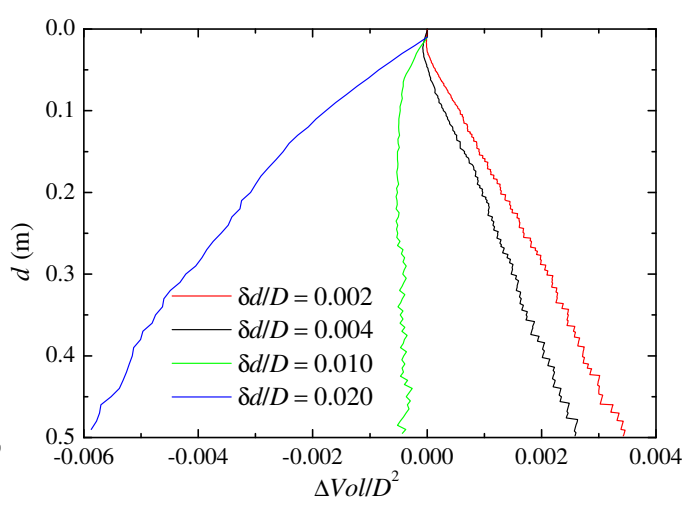

(b)

Figure 17. Influence of displacement increment $\delta d$ on wedge indentation response: (a) resistance; (b) normalised volume change. $\beta=60^{\circ}$ and $A_{\min }=0.001 d^{2}$.

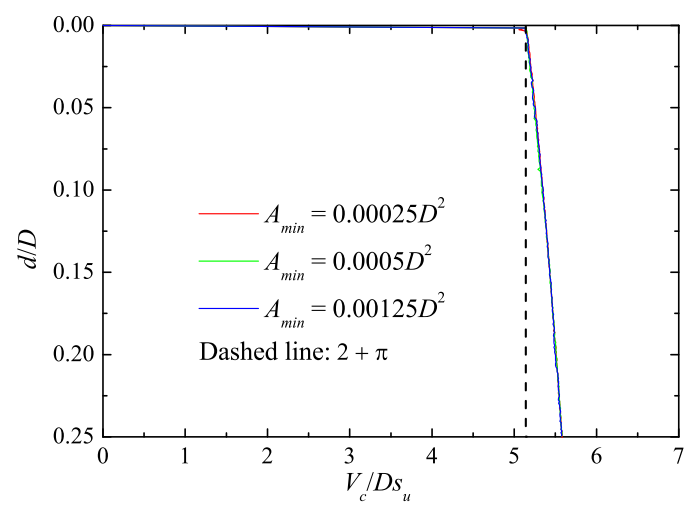

(a)

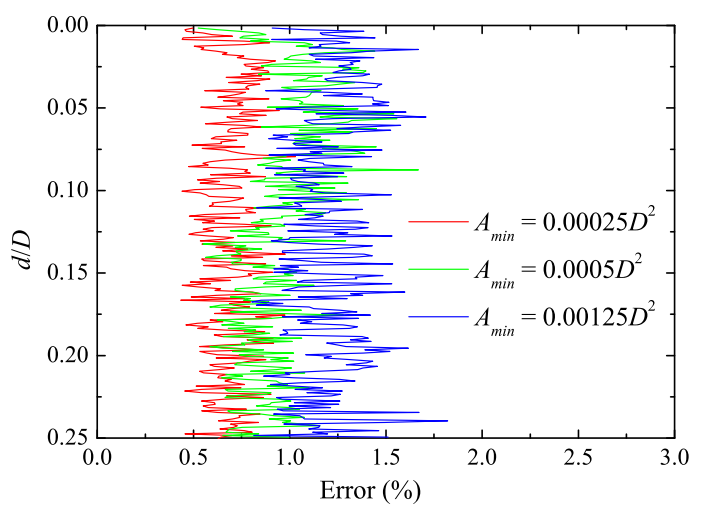

(b)

Figure 18. Influence of minimum element size $A_{\min }$ on strip footing indentation response: (a) normalised resistance; (b) normalised bracketing discrepancy. $\delta d / D=0.001$. 


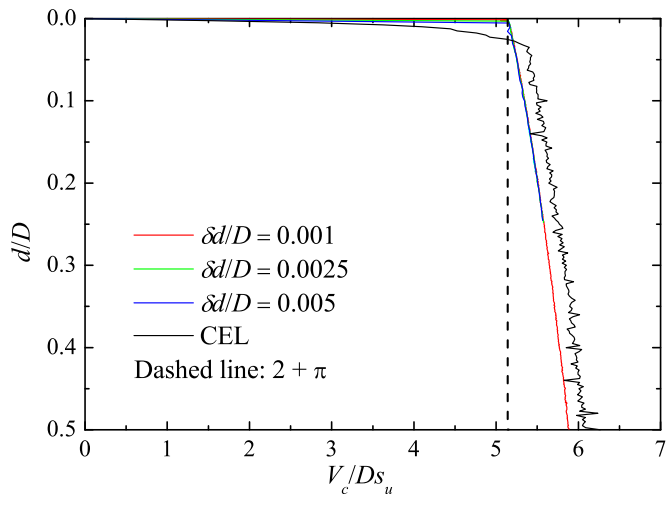

(a)

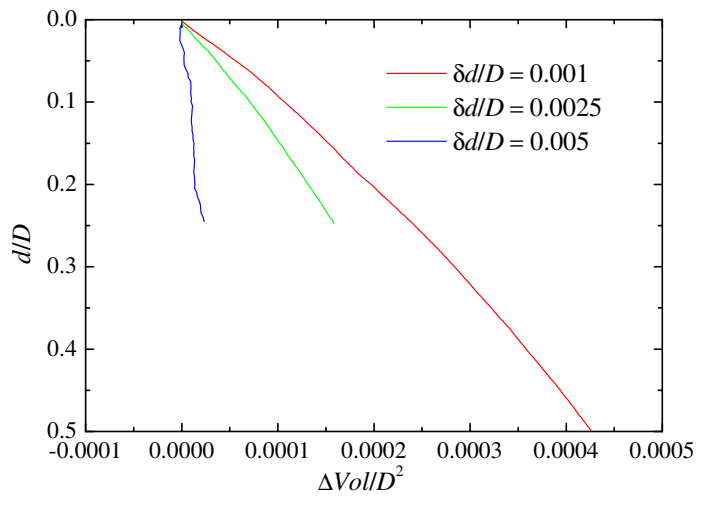

(b)

Figure 19. Influence of displacement increment $\delta d$ on strip footing indentation response: (a) normalised resistance; (b) normalised volume change. $A_{\min }=0.00025 D^{2}$.

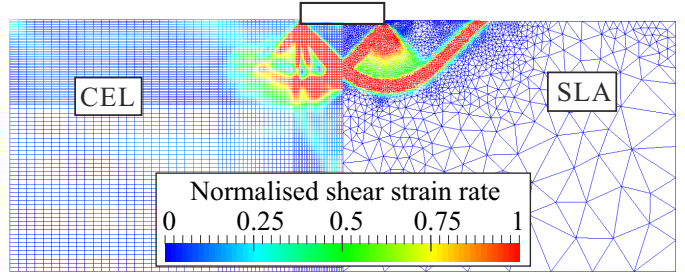

(a)

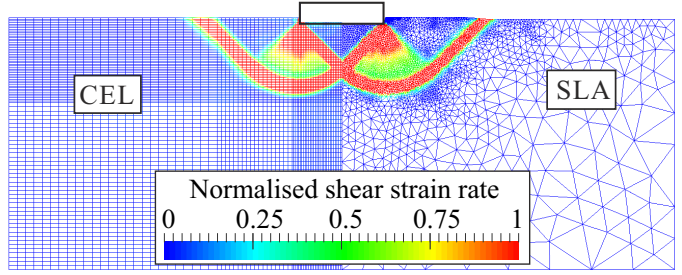

(b)

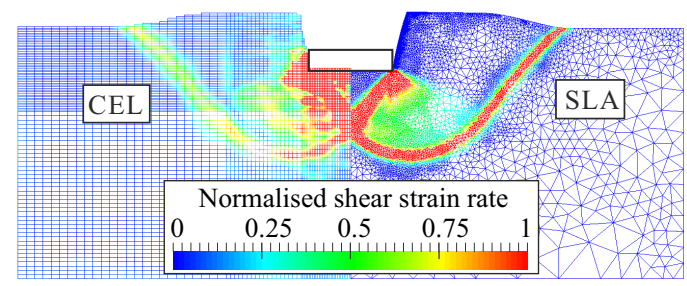

(c)

Figure 20. Soil failure mechanisms (contours of $\dot{\gamma} D / v_{p}$ ) for strip footing: (a) $d / D=0.03$; (b) $d / D=0.05$; (c) $d / D=0.5$. 


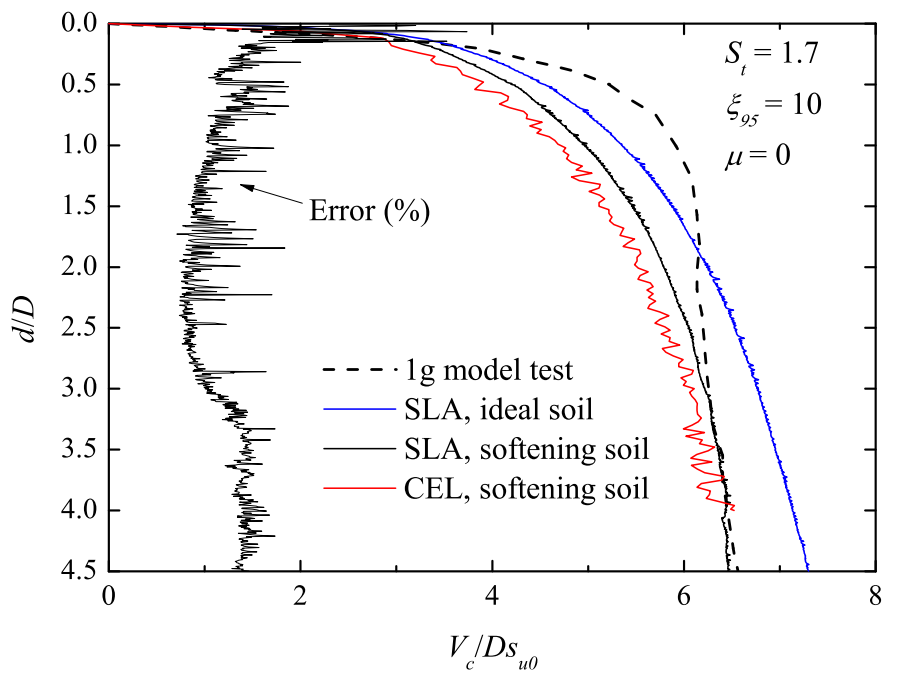

Figure 21. Indentation response of pipe (deep penetration): normalised resistance, also showing normalised bracketing discrepancy for SLA with softening soil.

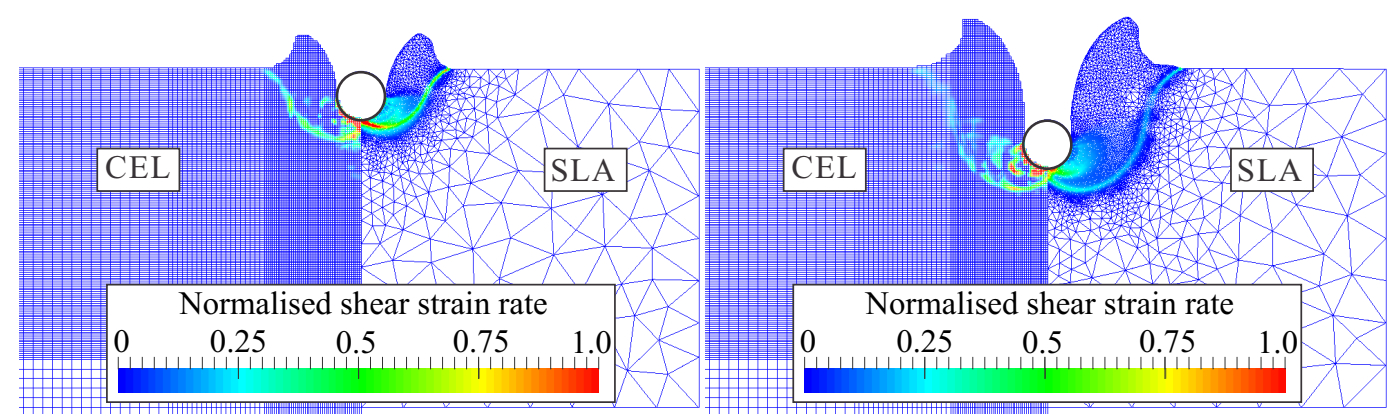

(a)

(b)

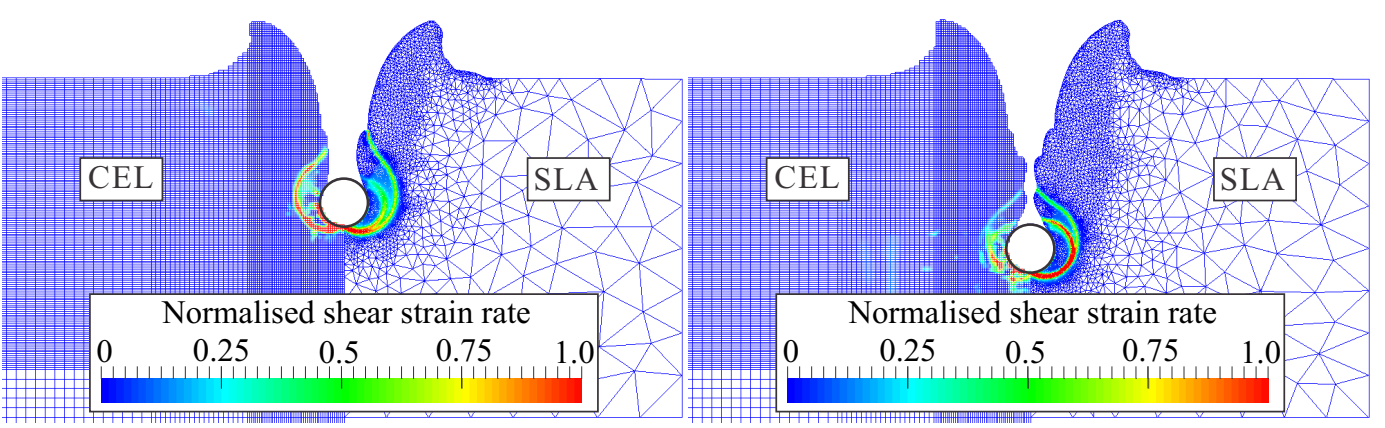

(c)

(d)

Figure 22. Soil failure mechanisms (contours of $\dot{\gamma} D / v_{p}$ ) for pipe (deep penetration): (a) $d / D=1$; (b)

$$
d / D=2 ;(\mathrm{c}) d / D=3 ;(\mathrm{d}) d / D=4 \text {. }
$$




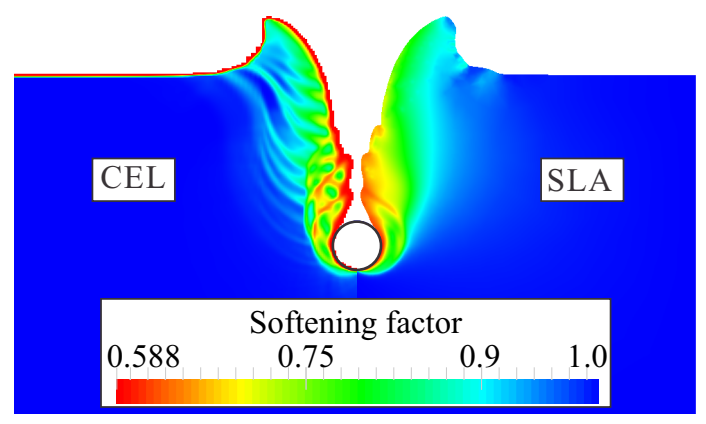

Figure 23. Softening factor for soil strength at end of deep pipe penetration $(d / D=4)$.

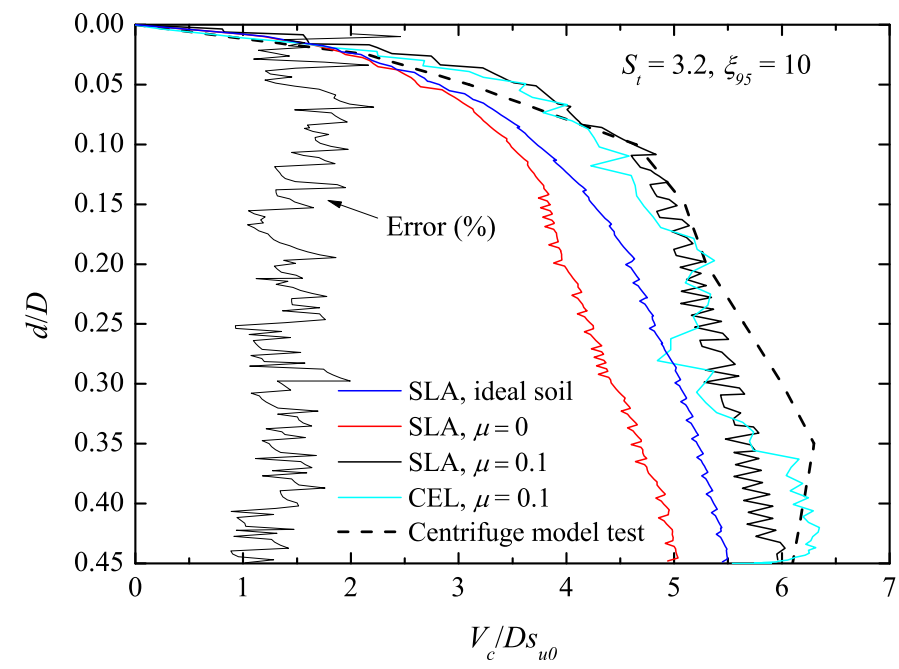

Figure 24. Indentation response of pipe (shallow penetration): normalised resistance, also showing normalised bracketing discrepancy for SLA with $\mu=0.1$.

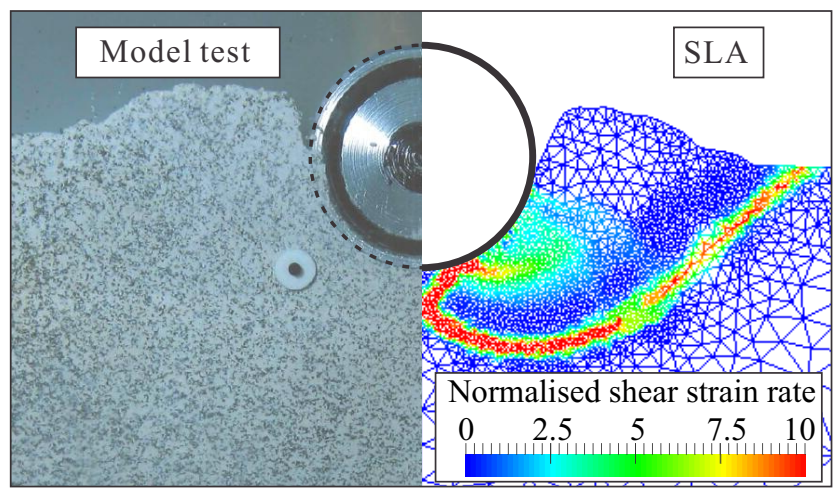

Figure 25. Soil failure mechanism (contours of $\left.\dot{\gamma} D / v_{p}\right)$ at end of shallow pipe penetration $(d / D=0.45)$. 


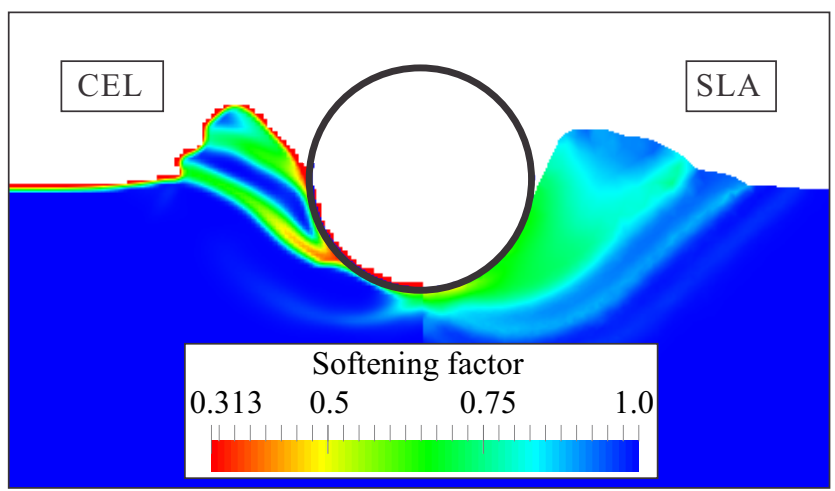

Figure 26. Softening factor for soil strength at end of shallow pipe penetration $(d / D=0.45)$.

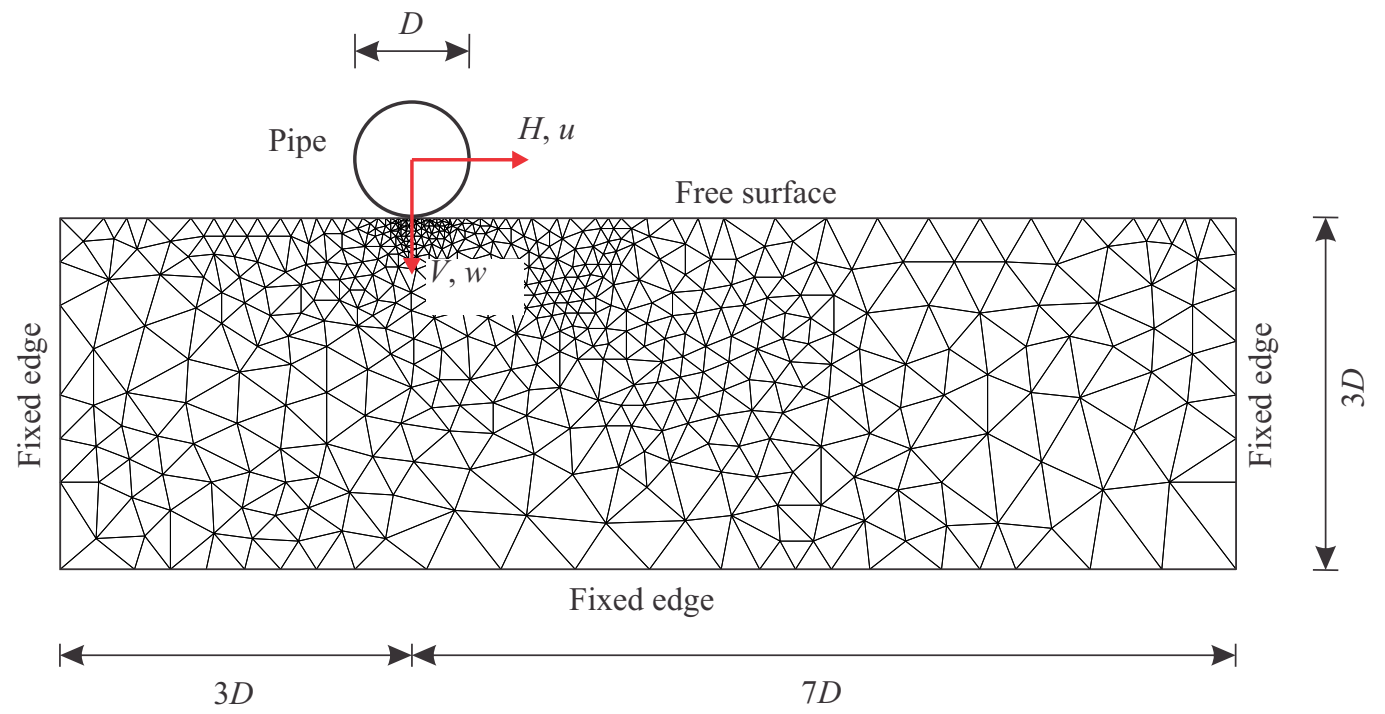

Figure 27. Initial configuration of SLA model for indentation and lateral loading of a pipe.

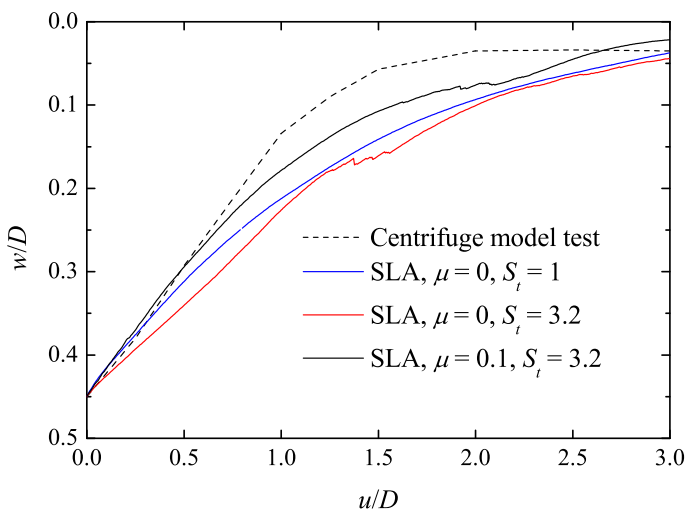

(a)

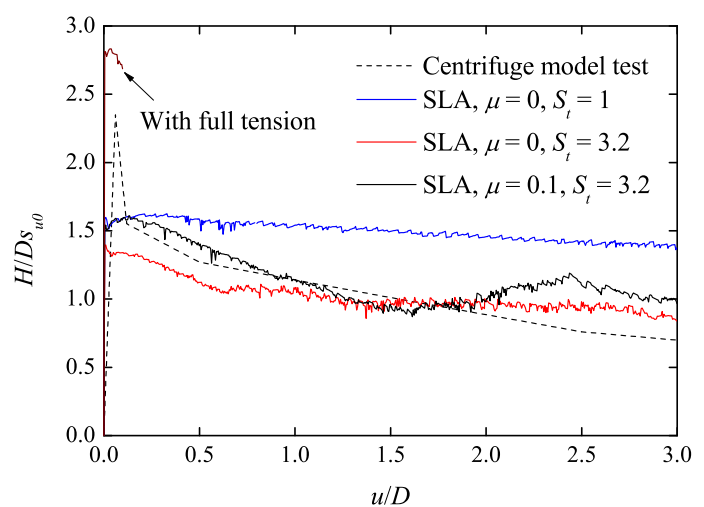

(b)

Figure 28. Lateral loading response of pipe: (a) invert trajectory; and (b) normalised lateral resistance. 


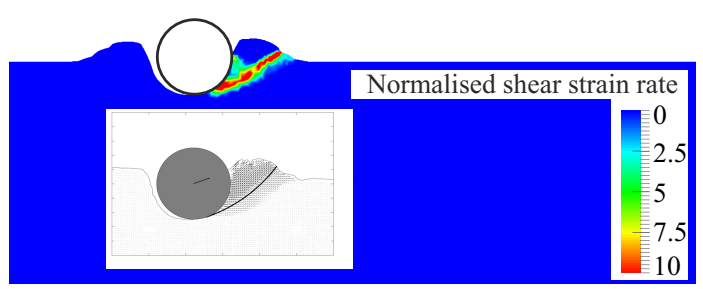

(a)

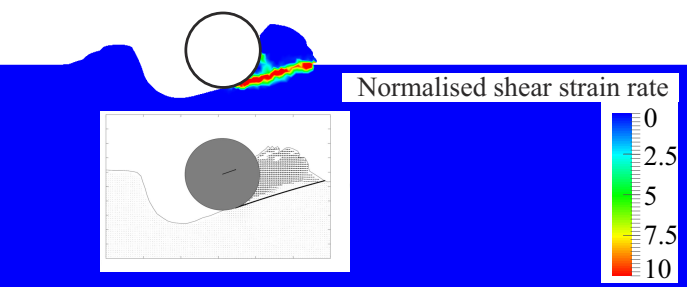

(b)

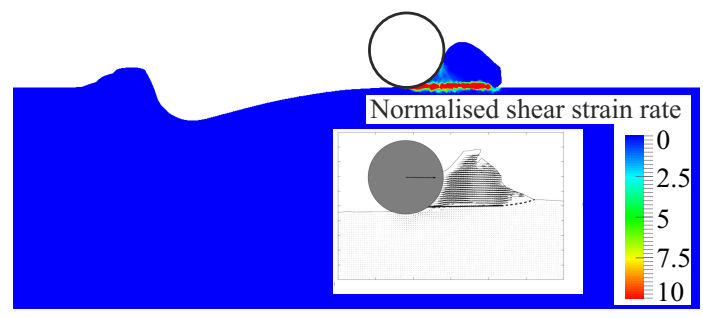

(c)

Figure 29. Soil failure mechanisms (contours of $\dot{\gamma} D / v_{p}$ ) during lateral loading of pipe: (a) $u / D=0.1$; (b)

$$
u / D=0.6 ; \text { (c) } u / D=2.9 \text {. }
$$

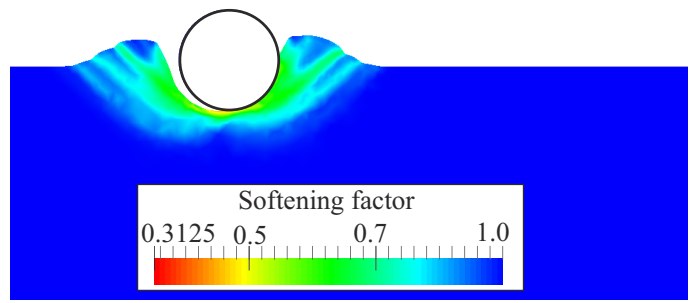

(a)

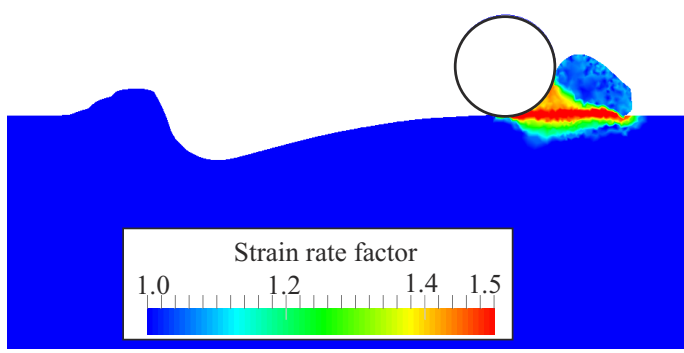

(c)

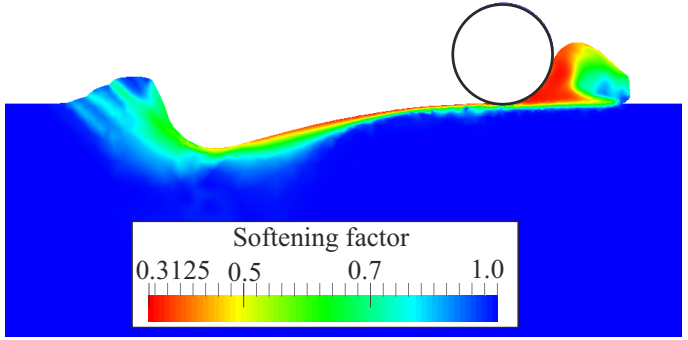

(b)

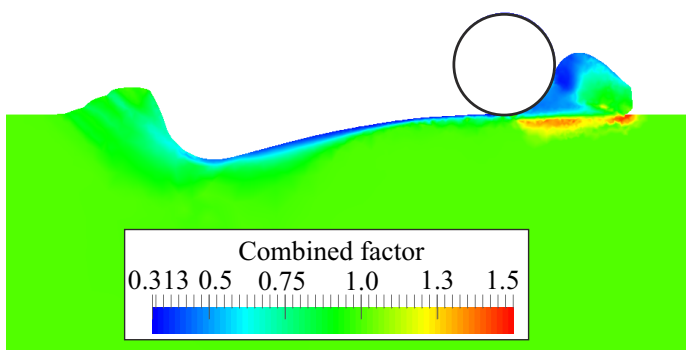

(d)

Figure 30. Softening and strain rate factors for soil strength during lateral loading of pipe: (a) softening factor at $u / D=0.1$; (b) softening factor at $u / D=2.9$; (c) strain rate factor at $u / D=2.9$; (d) combined factor at $u / D=2.9$. 


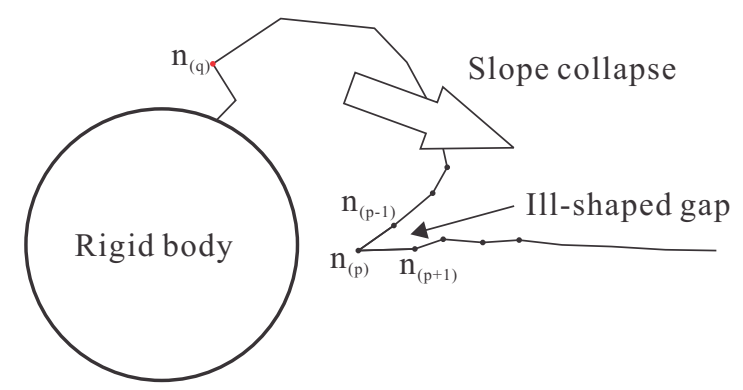

(a)

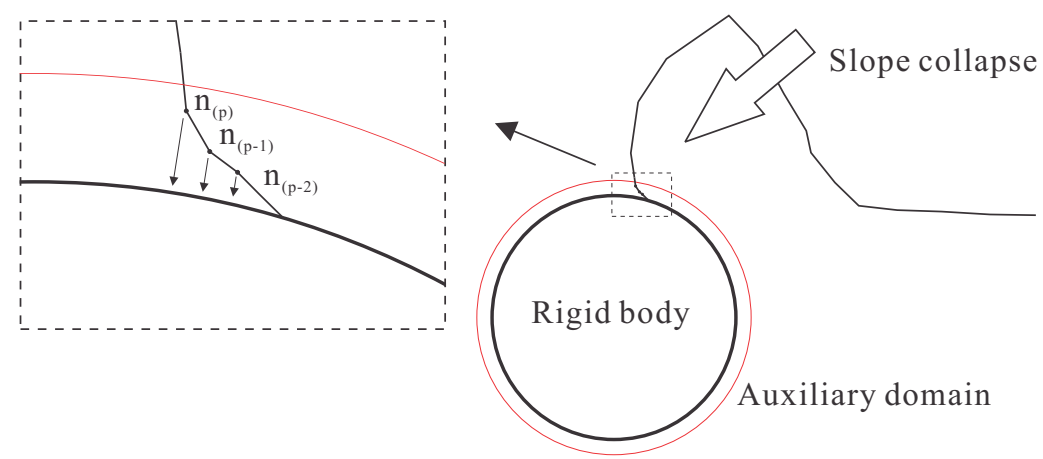

(b)

Figure 31. Conditions that may cause slope instability: (a) an ill-shaped gap; (b) a steep slope above the rigid body. 